Article

\title{
Effects of Sugars and Sugar Alcohols on the Gelatinization Temperatures of Wheat, Potato, and Corn Starches
}

\author{
Matthew C. Allan, MaryClaire Chamberlain 1 and Lisa J. Mauer* \\ Department of Food Science, Purdue University, 745 Agriculture Mall Drive, West Lafayette, IN 47907, USA; \\ wapatomatt@gmail.com (M.C.A.); mnchambe@ncsu.edu (M.C.) \\ * Correspondence: mauer@purdue.edu; Tel.: +1-(765)-494-9111
}

Received: 13 May 2020; Accepted: 3 June 2020; Published: 8 June 2020

check for updates

\begin{abstract}
The gelatinization temperature $\left(T_{\text {gel }}\right)$ of starch increases in the presence of sweeteners due to sweetener-starch intermolecular interactions in the amorphous regions of starch. Different starch botanical sources contain different starch architectures, which may alter sweetener-starch interactions and the effects of sweeteners on $\mathrm{T}_{\text {gel }} \mathrm{s}$. To document these effects, the $\mathrm{T}_{\text {gel }} \mathrm{s}$ of wheat, potato, waxy corn, dent corn, and $50 \%$ and $70 \%$ high amylose corn starches were determined in the presence of eleven different sweeteners and varying sweetener concentrations. $\mathrm{T}_{\text {gel }} \mathrm{S}$ of 2:1 sweetener solution:starch slurries were measured using differential scanning calorimetry. The extent of $\mathrm{T}_{\text {gel }}$ elevation was affected by both starch and sweetener type. $\mathrm{T}_{\text {gel }} \mathrm{s}$ of wheat and dent corn starches increased the most, while $\mathrm{T}_{\text {gel }} \mathrm{S}$ of high amylose corn starches were the least affected. Fructose increased $\mathrm{T}_{\text {gel }} \mathrm{S}$ the least, and isomalt and isomaltulose increased $\mathrm{T}_{\text {gel }} \mathrm{s}$ the most. Overall, starch $\mathrm{T}_{\text {gel }} \mathrm{s}$ increased more with increasing sweetener concentration, molar volume, molecular weight, and number of equatorial and exocyclic hydroxyl groups. Starches containing more short amylopectin chains, fewer amylopectin chains that span through multiple clusters, higher number of building blocks per cluster, and shorter inter-block chain lengths exhibited the largest $\mathrm{T}_{\text {gel }}$ increases in sweetener solutions, attributed to less stable crystalline regions.
\end{abstract}

Keywords: sugar; sugar alcohols; sweeteners; gelatinization; starch

\section{Introduction}

Starch granules are botanical energy storage vessels that differ in size $(2-100 \mu \mathrm{m})$ and molecular architecture between botanical sources, although all native starches share the traits of being semicrystalline, water insoluble, and composed predominantly of two $\alpha$-glucans: amylopectin and amylose [1-3]. Amylose is primarily a linear polysaccharide with a few branch points and a degree of polymerization (DP) ranging from 600 to 6000 [3]. Amylose resides in the amorphous regions of the starch granule, especially near the periphery, although some amylose may also be co-crystallized with amylopectin [2]. Amylopectin is a larger, branched molecule (5\% branching) that has a DP of 9600 to $>15,900$ [3]. The regions near amylopectin branches are amorphous, while the unbranched regions of amylopectin form crystalline, double helical structures [4]. These alternating amorphous and crystalline lamellae have a repeating distance of $\sim 9 \mathrm{~nm}$, regardless of the botanical source [5]. On a larger scale, starch granules also have alternating hard crystalline and softer semicrystalline growth rings (also known as shells) that are 100 to $400 \mathrm{~nm}$ thick [4]. Within these growth rings are blocklets that range in diameter from $20-500 \mathrm{~nm}$, with smaller blocklets in the semicrystalline growth rings and larger blocklets in the crystalline growth rings. In general, A-type crystalline starches (e.g., cereals) have smaller blocklets than B-type crystalline starches (e.g., tubers) [4,6]. The amorphous lamella and spaces between blocklets result 
in the semicrystalline starch structure (15-42\% crystalline). This allows for water to passively diffuse into the starch granule (up to 35\% moisture content wet basis in starch) and cause reversible swelling and plasticization [2,7]. With the application of sufficient thermal energy $\left(>57.1\right.$ to $72.0^{\circ} \mathrm{C}$ onset temperature range reported in Ratnayake and Jackson [8]), the molecular mobility in the amorphous regions is great enough to strip apart and melt the crystalline double helices in a process known as gelatinization $[9,10]$. The temperature at which this occurs is the gelatinization temperature $\left(T_{\text {gel }}\right)$.

Despite the commonality that starch gelatinization is the melting of amylopectin crystals, the $T_{\text {gel }} S$ of starches from different botanical sources vary [11]. Structural factors that influence the $T_{\text {gel }} \mathrm{s}$ of starches include: the crystalline form of starch [12], amount of crystal defects [13], amylopectin structure $[11,14,15]$, and amylose content $[16,17]$. Branch lengths of amylopectin have been extensively correlated with the $T_{\text {gel }} \mathrm{s}$ of starches: starches with higher amounts of short amylopectin chains (DP 6-12) have lower $\mathrm{T}_{\text {gel }} \mathrm{s}$, and starches with higher percentages of longer amylopectin chains (DP 14-25) have higher $\mathrm{T}_{\text {gel }} \mathrm{s}$ [18-20]. Additionally, starches with fewer building blocks (densely branched regions of amylopectin that precede double helices) per cluster (group of amylopectin branches in close proximity, NBbl) and greater spacing between these building blocks (IB-CL) have higher $\mathrm{T}_{\text {gel }} \mathrm{s}$ because these conformations favor more hydrogen bonding between double helices and resist plasticization during heating [11]. Therefore, the structure of amylopectin affects the thermal properties of starch, and starches with more stable amylopectin crystalline regions have higher $\mathrm{T}_{\text {gel }} \mathrm{s}$.

The presence of solutes, such as sugars, also affects the $\mathrm{T}_{\text {gel }}$. Early theories of why sugars increase the $T_{\text {gel }}$ were: sugars decrease the water activity $\left(a_{w}\right)$ and moisture content [21-23]; sugars increase the glass transition temperature $\left(\mathrm{T}_{\mathrm{g}}\right)$ of the amorphous fraction [24,25]; and sugar-starch intermolecular interactions stabilize starch [22,26-28]. These theories were evaluated using wheat starch and a variety of 19 sweeteners in a recent study by Allan, Rajwa and Mauer [29], who found that $T_{\text {gel }}$ increases were correlated to sweetener solution viscosity and the number of exocyclic and equatorial hydroxyl groups on the sweetener, and that $\mathrm{T}_{\text {gel }}$ increases were not strongly correlated to $\mathrm{a}_{\mathrm{w}}$ and dry sweetener $\mathrm{T}_{\mathrm{g}} \mathrm{s}$. In a follow-up study by van der Sman and Mauer [30], sweetener solution viscosity was correlated with the volumetric density of intermolecular hydrogen bonds; thus, the $\mathrm{T}_{\text {gel }}$ increase for wheat starch in sweetener solutions was presumed to be due to sweetener-starch intermolecular hydrogen bond interactions, with a greater number and strength of these interactions resulting in increased $\mathrm{T}_{\text {gel }} \mathrm{s}$.

The effects of sugars on $T_{\text {gel }}$ have largely been studied within the scope of a single starch type and without regard to the potential effects of starch granule differences between starch botanical sources and compositions. To expand on our earlier study of the effects of 19 sweeteners on wheat starch $\mathrm{T}_{\text {gel }}$ [29], the objective of this study was to investigate the effects of different sweeteners on the $\mathrm{T}_{\text {gel }} \mathrm{s}$ of six starches with varying granule morphologies (crystal type, percent crystallinity, amylose content, amylopectin chain length distribution, NBbl, and IB-CL) to elucidate the effects of starch botanical sources (and hence structure) on sweetener-starch interactions and resultant $\mathrm{T}_{\text {gel }}$ elevation.

\section{Materials and Methods}

\subsection{Materials}

Melojel ${ }^{\circledR}$ dent corn starch (dent corn), Amioca waxy corn starch (waxy corn), PenPure ${ }^{\circledR} 10$ potato starch (potato), Hylon ${ }^{\circledR}$ VII high amylose ( $\approx 70 \%$ amylose) corn starch (HACS70), and Hylon ${ }^{\circledR} \mathrm{V}$ high amylose $(\approx 55 \%$ amylose) corn starch (HACS55) were donated by Ingredion Inc. (Westchester, IL, USA), and Aytex ${ }^{\circledR}$ P wheat starch was donated by ADM (Minneapolis, MN, USA) (Table 1). All starches were unmodified and used "as is". Eleven different sugars and sugar alcohols that are commonly used as food ingredients and/or have minor stereochemical differences of interest for this study were used: glucose, galactose, fructose, and mannose from Acros Organics (Fair Lawn, NJ, USA); trehalose dihydrate from Hayashibara Company (Okayama, Japan); maltose monohydrate from Fisher Bioreagents (Fair Lawn, NJ, USA); isomaltulose monohydrate and isomalt from BENEO-Palatinit Gmbh (Mannheim, Germany); sucrose from Mallinckrodt Chemicals (Phillipsburg, NJ, USA); and maltitol 
and sorbitol from Alfa Aesar (Ward Hill, MA, USA) (Table 1). Sodium hydroxide (NaOH) was from Sigma-Aldrich (St. Louis, MO, USA), and hydrochloric acid $(37 \%)(\mathrm{HCl})$ was from Acros Organics. The water used in this study was processed using reverse osmosis, then filtered by a Barnstead E-Pure Lab Water System (Dubuque, IA, USA) to $>17.4$ milliohm-cm.

\subsection{Methods}

\subsubsection{Sweetener Solutions}

The 6-carbon (6-C) sweeteners studied consisted of aldoses (glucose, mannose, galactose), a ketose (fructose), and an alditol (sorbitol). Solutions were prepared at 1, 2,3, and 4 molar (M) concentrations for the 6-C sweeteners except for galactose, for which only 1 and $2 \mathrm{M}$ solutions were used due to solubility limitations. The 12-carbon (12-C) sweeteners consisted of reducing sugars (maltose, isomaltulose), non-reducing sugars (trehalose, sucrose), and sugar alcohols (isomalt, maltitol), and solutions were prepared at $0.5,1.0$, and $1.5 \mathrm{M}$ concentrations, with an additional $2.0 \mathrm{M}$ sucrose solution. The sweetener solutions were prepared in $10 \mathrm{~mL}$ volumes in $15 \mathrm{~mL}$ centrifuge tubes. Water was added to the sweetener to $\sim 80 \%$ of the final volume, then the tube was placed in a heating block at $80^{\circ} \mathrm{C}$ for several minutes followed by vortexing on a VWR Vortex Mixer (Lebanon, NJ, USA) and/or slower rotational mixing using a Scientific Industries Roto-Shake Genie (Bohemia, NY) until the sweetener fully dissolved. Upon cooling to near ambient temperature, water was added to reach a final $10 \mathrm{~mL}$ volume. Solutions were not used if crystals were visible after overnight storage at ambient conditions.

\subsubsection{Gelatinization Temperature $\left(T_{\text {gel }}\right)$}

The gelatinization temperatures $\left(\mathrm{T}_{\text {gel }} \mathrm{s}\right)$ of the starch-sweetener slurries were measured using a method adapted from Allan, Rajwa and Mauer [29]. Approximately $250 \mathrm{mg}$ of 1:2 w/w starch slurries were made by combining 1 part starch with precisely 2 parts solution in $1.5 \mathrm{~mL}$ centrifuge tubes, mixing with a stainless steel pin, and vortexing until the slurry appeared to be a homogenous mixture (no visible dry starch). The samples were then capped and stored overnight at ambient temperature $\left(\sim 22^{\circ} \mathrm{C}\right)$. Before analysis, samples were vortexed to re-suspend the starch, and 15 to $20 \mathrm{mg}$ of slurry were transferred into a Perkin Elmer $50 \mu \mathrm{L}$ pan (BO143017) and hermetically sealed with a lid (BO143003). Due to analysis temperatures exceeding $115^{\circ} \mathrm{C}$ and risk of pan failure, the HACS70 and HACS55 samples were loaded into high-pressure Perkin Elmer $50 \mu \mathrm{L}$ pans (B016-9321) and hermetically sealed with high-pressure lids (B016-9321). Pans were manually transferred into a Perkin Elmer DSC 4000 (Waltham, MA, USA) that was calibrated using water, indium, and zinc. The potato, dent corn, and waxy corn samples were heated from $30^{\circ} \mathrm{C}$ up to $100-115^{\circ} \mathrm{C}$ at $10^{\circ} \mathrm{C} / \mathrm{min}$, while HACS70 and HACS55 samples were heated from $30{ }^{\circ} \mathrm{C}$ up to $115-130{ }^{\circ} \mathrm{C}$ at $10{ }^{\circ} \mathrm{C} / \mathrm{min}$. The $\mathrm{T}_{\text {gel }}$ of each slurry was measured in triplicate. The $\mathrm{T}_{\text {gel }}$ was identified as the endothermic event occurring around 60 to $103^{\circ} \mathrm{C}$, and the onset temperature, peak temperature, and enthalpy $(\Delta \mathrm{H})$ of starch gelatinization were determined using the "peak calculation" function with the "Standard" baseline in Pyris Software (version 10.1.0.0412). $\mathrm{T}_{\text {gel }}$ peak analysis was performed using data that encompassed $\sim 5$ to $10^{\circ} \mathrm{C}$ before the peak onset to the post peak heat flow maxima ( 2 to $5{ }^{\circ} \mathrm{C}$ after the peak end) (Figure S1) while ensuring the peak analysis baseline did not cut through or go under any part of the thermogram. The onset of the $T_{\text {gel }}$ peak was calculated by the Pyris software as the intersection of the tangent of the baseline before the peak with the tangent of the inflection of the leading side of the peak (Figure S1). The $\Delta \mathrm{H}$ of gelatinization was the measured area of the peak, and the reported $\mathrm{J} / \mathrm{g}$ was of the $1: 2 \mathrm{w} / \mathrm{w}$ starch solution slurry (not adjusted to J/g of dry starch). The onset $\mathrm{T}_{\text {gel }}$ of HACS70 was calculated using the "onset" function due to lack of a clear end of peak and/or only partial gelatinization occurring within the experimental parameters. This onset was determined by the intersection of two tangents, where the 1st tangent was the slope before gelatinization and the 2nd tangent was the slope between the onset and peak. Examples of DSC analysis for starch in water are shown in Figure S1. Since some samples lacked a clear endotherm peak, the onset $\mathrm{T}_{\text {gel }} \mathrm{S}$ were compared further in this study. 
Table 1. Physical and chemical properties of the starches used in this study

\begin{tabular}{|c|c|c|c|c|c|c|c|c|c|c|c|c|c|c|}
\hline \multirow[b]{2}{*}{ Starch } & \multirow[b]{2}{*}{$\begin{array}{c}\mathrm{T}_{\text {gel }} \text { Onset } \\
\left({ }^{\circ} \mathrm{C}\right)^{+}\end{array}$} & \multirow[b]{2}{*}{$\begin{array}{c}\text { Percent } \\
\text { Crystallinity } \ddagger\end{array}$} & \multirow[b]{2}{*}{$\begin{array}{l}\text { Crystal } \\
\text { Type [2] }\end{array}$} & \multicolumn{2}{|c|}{ Amylose Content [2] } & \multirow{2}{*}{$\begin{array}{c}\text { Average } \\
\begin{array}{c}\text { Chain Length } \\
\text { (DP) [2] }\end{array}\end{array}$} & \multirow[b]{2}{*}{ DP 6-12 } & \multicolumn{2}{|c|}{ \% Distribution [2] } & \multirow[b]{2}{*}{$\mathrm{DP} \geq 37$} & \multirow[b]{2}{*}{ NBbl } & \multirow[b]{2}{*}{ IB-CL } & \multirow{2}{*}{$\begin{array}{c}\text { Granule } \\
\text { Size } \\
(\mu \mathrm{m})[1]\end{array}$} & \multirow{2}{*}{$\begin{array}{c}\text { Phosp- } \\
\begin{array}{c}\text { Horus } \\
\text { (\%DS) [1] }\end{array}\end{array}$} \\
\hline & & & & Apparent & Absolute & & & $\begin{array}{c}\text { DP } \\
13-24\end{array}$ & $\begin{array}{c}\text { DP } \\
25-36\end{array}$ & & & & & \\
\hline Waxy corn & $65.84 \pm 0.25 \mathrm{~B}$ & 41.8 [31] & A & $<1 \%$ & $<1 \%$ & 23.5 & 17.0 & 49.4 & 17.1 & 16.5 & $5.2[32]$ & 6.2 [32] & $2-30$ & 0.00 \\
\hline Dent corn & $66.19 \pm 0.65 \mathrm{~B}$ & 30.3 [31] & A & 29.4 & 22.5 & 24.4 & 17.9 & 47.9 & 14.9 & 19.3 & 6.2 [33] & 6.8 [33] & $2-30$ & 0.00 \\
\hline HACS55 & $71.81 \pm 0.25 \mathrm{C}$ & $19.5[31]$ & B & 52 & 27.3 & 28.9 & 9.7 & 43.9 & 20.3 & 26.1 & $5.4[33]$ & $9.1[33]$ & $2-24$ & 0.00 \\
\hline HACS70 & $71.27 \pm 0.37 \mathrm{C}$ & $20.7[34]$ & B & 68 & 40.2 & 30.7 & 8.5 & 40.7 & 21.3 & 29.5 & $5.6[33]$ & 8.9 [33] & $2-24$ & 0.00 \\
\hline Potato & $61.32 \pm 0.19 \mathrm{~A}$ & $45.5[34]$ & B & 36 & 16.9 & 29.4 & 12.3 & 43.3 & 15.5 & 28.9 & $3-5[35]$ & $7-8[35]$ & 5-100 & 0.08 \\
\hline Wheat & $60.78 \pm 0.09 \mathrm{~A}$ & $22.8[34]$ & A & 28.8 & 25.8 & 22.7 & 19.0 & 41.7 & 16.2 & 13.0 & $6.2-6.3[36]$ & $6.4-6.5[36]$ & $2-55$ & 0.00 \\
\hline
\end{tabular}

${ }^{+} \mathrm{T}_{\text {gel }} \mathrm{s}$ in water. Capital letters indicate statistical groupings. ${ }^{\ddagger}$ Percent crystallinity data were from reported \% crystallinity values calculated using X-ray diffractograms. DP: degree of polymerization. 
The effects of $\mathrm{pH}$ on the $\mathrm{T}_{\text {gel }}$ of potato starch in $1 \mathrm{M}$ glucose solutions were determined using a modified sample preparation method prior to DSC analysis. An initial $150 \mathrm{~g}$ sample of a 1:2 w/w starch slurry made with $1 \mathrm{M}$ glucose was mixed in a $250 \mathrm{~mL}$ beaker, and then the $\mathrm{pH}$ was adjusted to $4,5,6,7,8,9$, and 10 using $1 \mathrm{M}$ glucose solutions that had been $\mathrm{pH}$-adjusted using $1 \mathrm{M} \mathrm{NaOH}$ or $1 \mathrm{M} \mathrm{HCl}$. The $\mathrm{pH}$ was measured using an Orion $\mathrm{pH}$ probe (ThermoScientific, Waltham, MA, USA) calibrated from $\mathrm{pH} 4$ to 10 . The $\mathrm{pH}$ of the slurry was adjusted rather than the glucose solution to avoid any unaccounted $\mathrm{pH}$ buffering from the phosphates in the potato starch. The final starch-to-slurry $w / w$ ratio was no longer precisely 1:2 $w / w$ due to the addition of the acidified and alkalinized $1 \mathrm{M}$ glucose solutions, but this was not a major concern since the $T_{\text {gel }}$ onset in an abundance of solution is not affected by minor starch:solution ratio changes [37]. The slurries were equilibrated overnight, and the $\mathrm{T}_{\text {gel }}$ of each $\mathrm{pH}$-controlled slurry was then measured in triplicate.

\subsubsection{Data Analysis}

The effects of sweeteners on the $\mathrm{T}_{\text {gel }}$ of a starch were compared by grouping the $\mathrm{T}_{\mathrm{gel}} \mathrm{S}$ of a starch in sweetener solutions with equal monosaccharide unit concentrations (e.g., $1 \mathrm{M}$ monosaccharide and $0.5 \mathrm{M}$ disaccharide solutions were grouped together), followed by one-way ANOVA and Tukey post-hoc tests $(\alpha=0.05)$. The effects of a sweetener solution on the $\mathrm{T}_{\text {gel }} \mathrm{s}$ of different starches were

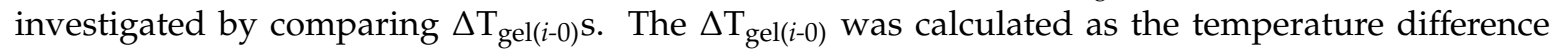
between the $T_{\text {gel }}$ of a starch in a sweetener solution to that in water. Significant differences of $\Delta T_{\text {gel }(i-0)} S$ between starches in a sweetener solution were identified using one-way ANOVA and Tukey post-hoc tests $(\alpha=0.05)$. The $\mathrm{T}_{\text {gel }} \mathrm{S}$ of potato starch in $1 \mathrm{M}$ glucose solutions at $\mathrm{pHs} 4-10$ were also compared using one-way ANOVA and Tukey post-hoc tests $(\alpha=0.05)$. The associations of categorical sweetener solution properties to effects on $\mathrm{T}_{\text {gel }} \mathrm{s}$ were investigated using four-way ANOVA with all possible two-way interactions $(\alpha=0.05)$. The categorical sweetener solution properties were: monosaccharide unit concentration (e.g., $1 \mathrm{M}$ was $1 \mathrm{M}$ mono- and $0.5 \mathrm{M}$ disaccharide solutions), sweetener size (6-C or 12-C), sweetener type (sugar or sugar alcohol), and if the sweetener was a reducing sugar. The correlation of quantitative starch (Table 1) and sweetener solution properties (Table 2) to the $T_{\text {gel }} \mathrm{S}$ were investigated using linear correlations and $t$-statistics. The tested quantitative starch properties were: percent crystallinity, amylose content (apparent and absolute), average amylopectin chain length, percentage of DP 6-12, percentage of DP 13-24, percentage of DP 25-36, percentage of DP $\geq 37$, number of building blocks per cluster (NBbl), and inter-block chain lengths (IB-CL). The quantitative sweetener solution properties were: number of hydroxyl groups for intermolecular $\mathrm{H}$-bonding $\left(\mathrm{N}_{\mathrm{OH}, \mathrm{s}}\right)$, number of equatorial and exocyclic hydroxyl groups, dry glass transition $\left(\mathrm{T}_{\mathrm{g}}\right)$, sweetener molar volume, and capacity factor $\left(K_{c}\right)$ (Table 2). These starch and sweetener properties were correlated with the $\Delta \mathrm{T}_{\text {gel }(i-0)} \mathrm{s}$ in sweetener solutions at $3 \mathrm{M}$ monosaccharide unit concentrations $\left(\Delta \mathrm{T}_{\text {gel }(3 \mathrm{M}-0)}\right)$ and with the slope of the $\log _{10}$ of $\mathrm{T}_{\text {gel }} \mathrm{S}$ in respect to molar monosaccharide unit concentrations $\left(\log \mathrm{T}_{\text {gel }} \mathrm{s}\right)$. The significance of the Pearson correlation coefficient $(\mathrm{R})$ was assessed using $t$-statistics:

$$
t=\frac{\mathrm{R}}{\sqrt{\frac{1-\mathrm{R}^{2}}{n-2}}}
$$

with $n-2$ degrees of freedom. The significance of crystalline starch type (A or B-type) was evaluated using a two-tailed $t$-test. The effective water contents $\left(\phi_{w}\right.$, eff $)$ of sweetener solutions were extracted from van der Sman and Mauer [30]. All ANOVA tests were performed using IBM SPSS Statistics v. 26.0.00 (Armonk, NY, USA), and correlations and $t$-statistics were calculated using Microsoft Excel 365 (Redmond, WA, USA). 
Table 2. Properties of the sweeteners used in this study.

\begin{tabular}{|c|c|c|c|c|c|c|c|c|c|}
\hline Sweetener & $\begin{array}{l}\text { Number of } \\
\text { Carbons }\end{array}$ & $\begin{array}{c}\text { Sweetener } \\
\text { Type }\end{array}$ & $\begin{array}{l}\text { Reducing } \\
\text { Sugar }\end{array}$ & $\begin{array}{c}\text { Glycosidic } \\
\text { Linkage [38] }\end{array}$ & $\begin{array}{l}\text { Number of } \mathrm{OH} \\
\text { Groups for } \\
\text { Inter-Molecular } \\
\text { H-Bonding [30] }\end{array}$ & $\begin{array}{l}\text { Calculated Equatorial } \\
\text { and Exo-Cyclic OHs in } \\
\text { Solution [29] }\end{array}$ & $\begin{array}{l}\text { Dry Tg } \\
\left({ }^{\circ} \mathrm{C}\right)[39]\end{array}$ & $\begin{array}{l}\text { Molar Volume } \\
\left(\mathrm{cm}^{3} / \mathrm{mol}\right)\end{array}$ & $\begin{array}{l}\text { Capacity Factor } \\
\left(K_{c}\right)[40]\end{array}$ \\
\hline Fructose & 6 & Sugar & Yes & NA & 3.98 & 2.8 & $15.16 \pm 0.11$ & $110.4 \pm 0.4[39]$ & 0.029 \\
\hline Mannose & 6 & Sugar & Yes & NA & 4.05 & 3.3 & $35.91 \pm 0.10$ & $111.7 \pm 0.5[39]$ & 0.026 \\
\hline Galactose & 6 & Sugar & Yes & NA & 3.95 & 3.6 & $31.92 \pm 0.47$ & $111.9 \pm 0.3[39]$ & -0.006 \\
\hline Glucose & 6 & Sugar & Yes & NA & 3.98 & 4.6 & $38.30 \pm 0.01$ & $112.2 \pm 0.4[39]$ & 0.016 \\
\hline Sorbitol & 6 & Sugar Alcohol & No & $\mathrm{NA}$ & 3.21 & 6 & $-1.54 \pm 0.71$ & 119.9 [41] & 0.012 \\
\hline Sucrose & 12 & Sugar & No & $\alpha \operatorname{Glc} p(1 \rightarrow 2) \beta$ Fruf & 4.48 & 6 & $59.36 \pm 0.56$ & $210.2 \pm 0.8[39]$ & 0.47 \\
\hline Isomaltulose & 12 & Sugar & Yes & $\alpha \operatorname{Glc} p(1 \rightarrow 6)$ Fru & 4.75 & 5.2 & $60.56 \pm 0.61$ & 219.5 [42] & 0.177 \\
\hline Isomalt & 12 & Sugar Alcohol & No & $\begin{array}{c}\alpha \mathrm{Glcp}(1 \rightarrow 6) \text { Sor \& } \\
\alpha \mathrm{Glcp}(1 \rightarrow 6) \mathrm{Mtl}\end{array}$ & 4.69 & 9 & $58.73 \pm 1.63$ & NA & 0.1260 .143 \\
\hline Trehalose & 12 & Sugar & No & $\alpha \operatorname{Glc} p(1 \rightarrow 1) \alpha \operatorname{Gl} c p$ & 7.72 & 8 & $117.51 \pm 2.01$ & $206.9 \pm 0.5[39]$ & 0.128 \\
\hline Maltose & 12 & Sugar & Yes & $\alpha \operatorname{Glc} p(1 \rightarrow 4)$ Glc & 5.74 & 7.4 & $48.99 \pm 3.83$ & $208.8 \pm 0.8[39]$ & 0.195 \\
\hline Maltitol & 12 & Sugar Alcohol & No & $\alpha \operatorname{Glcp}(1 \rightarrow 4)$ Sor & 4.33 & 9 & $46.40 \pm 0.11$ & $215.36^{7}[43]$ & NA \\
\hline
\end{tabular}

NA: not available. 


\section{Results and Discussion}

\subsection{Effects of Sweetener Properties on the Gelatinization Temperatures of Starches}

\subsubsection{Wheat Starch}

The presence of a sweetener in solution increased the $\mathrm{T}_{\text {gel }}$ of wheat starch, and increasing sweetener concentrations resulted in further increases in $\mathrm{T}_{\text {gel }}$ (Figure 1). For example, from a starting point of $60.78^{\circ} \mathrm{C}$ in water, the $\mathrm{T}_{\text {gel }}$ of wheat starch increased by $3.54,11.50,19.20$, and $28.86{ }^{\circ} \mathrm{C}$ in $0.5,1.0,1.5$, and 2.0 M sucrose solutions (Figures 1 and 2, Table S1). The type of sweetener also had a significant effect on the wheat starch $\mathrm{T}_{\text {gel }}$. In $3 \mathrm{M}$ monosaccharide unit solutions, fructose and mannose increased the $\mathrm{T}_{\text {gel }}$ the least, whereas isomaltulose followed by sucrose, isomalt, maltitol, and trehalose increased the $\mathrm{T}_{\text {gel }}$ the most (Figure 1 and Table S1). The 12-C sweeteners typically increased the wheat starch $\mathrm{T}_{\text {gel }}$ more than 6-C sweeteners when compared at equal monosaccharide unit concentrations, except for sorbitol which increased the $\mathrm{T}_{\text {gel }}$ more than maltose (Table 3 and Table S1). The gelatinization endotherm of wheat starch remained as a single unimodal peak in the presence of sweeteners (Figure 2). Therefore, unlike what is found in low moisture conditions where additional thermal energy is needed to fully melt amylopectin, there was no peak separation between G (solution mediated melting of crystallites that is independent of moisture content) and M1 (melting of remaining crystallites that is dependent on moisture content) $[37,44]$-increasing sweetener concentrations simply increased the $\mathrm{T}_{\text {gel }}$ endotherm to a higher temperature.

Sugar alcohols tended to increase the wheat starch $\mathrm{T}_{\text {gel }}$ more than the sugar counterparts at the same molar concentrations (e.g., Figure 1 and Table S1, sorbitol vs. glucose), except between isomalt and isomaltulose. In Allan, Rajwa and Mauer [29], the wheat starch $\mathrm{T}_{\text {gel }} \mathrm{s}$ in xylitol solutions were also significantly higher than in xylose solutions and sugar alcohols were speculated to increase the wheat starch $\mathrm{T}_{\text {gel }}$ more than sugars by potentially forming more $\mathrm{H}$-bonds within the amorphous regions of native starch. Sugar alcohols may form more sweetener-starch interactions because they have an open structure [45], greater molar volume, and greater number of exocyclic hydroxyl groups (Table 2) than sugars.

The quantitative sweetener properties in Table 2 were also compared to the sweetener effects on wheat starch $\mathrm{T}_{\text {gel }}$ in $3 \mathrm{M}$ monosaccharide unit sweetener solutions $\left(\Delta \mathrm{T}_{\text {gel(3M-0) }}\right)$ and the slope of the log of $\mathrm{T}_{\text {gel }} \mathrm{S}$ with respect to the sweetener molar monosaccharide unit concentration $\left(\log \mathrm{T}_{\text {gel }}\right)$. Significant correlations $(p<0.10)$ were found between $\mathrm{T}_{\text {gel }}$ increases in sweetener solutions and both the number of equatorial and exocyclic hydroxyl groups on the sweetener and the sweetener molar volume, whereas the correlations of $\mathrm{T}_{\text {gel }}$ with $\mathrm{N}_{\mathrm{OH}, \mathrm{s}}, \mathrm{T}_{\mathrm{g}}$, and $K_{\mathrm{c}}$ were not significant (Table 4). The correlation between wheat starch $\mathrm{T}_{\text {gel }}$ and the number of equatorial and exocyclic hydroxyl groups suggests that sweetener stereochemistry influences the $\mathrm{T}_{\text {gel }}$ increase. Similar findings were found for sweetener-water interactions, for which there was a strong correlation between the number of equatorial hydroxyl groups and dynamic hydration number of a sweetener [46]. The sweetener stereochemistry affects intermolecular H-bonding tendencies because exocyclic and equatorial hydroxyl groups are more reactive than the axial hydroxyl groups [47], and the strength and number of sweetener-starch interactions affect the $\mathrm{T}_{\text {gel }}$ increase [29]. The sweetener molar volume was also significantly correlated to the effects on wheat starch $\mathrm{T}_{\text {gel }}$ (Table 4$)$, as were the sweetener solution viscosities $(\mathrm{R} \geq 0.96$, Table S2). Overall, 12-C sweeteners had larger solute radii and increased the $\mathrm{T}_{\text {gel }}$ more than 6-C sweeteners, and sugar alcohols had larger radii and increased the $\mathrm{T}_{\text {gel }}$ more than their sugar counterparts (Tables 2 and 4). Conceptually, sweeteners with larger solute radii can form longer H-bond bridges between chains in the amorphous regions of native starch and therefore have a greater stabilizing effect. 


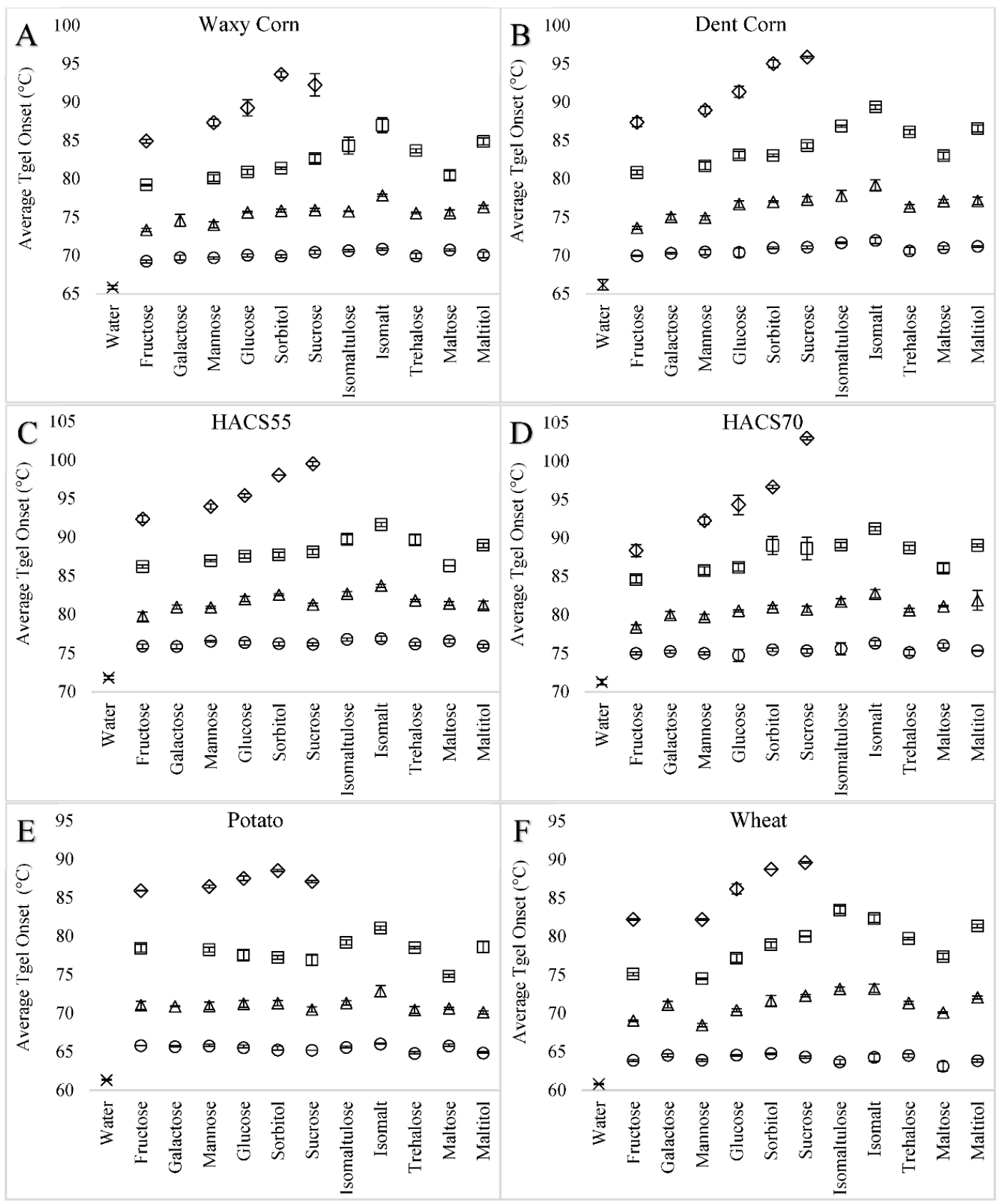

Figure 1. Effects of sweetener type and concentration in solution on the onset $\mathrm{T}_{\text {gel }} \mathrm{S}$ of different starches: (A) waxy corn, (B) dent corn, (C) HACS55, (D) HACS70, (E) potato, and (F) wheat starch. Sweetener solutions are grouped by similar solids content: $1 \mathrm{M}$ mono-, $0.5 \mathrm{M}$ disaccharide solutions $(\bigcirc) ; 2 \mathrm{M}$ mono-, $1 \mathrm{M}$ disaccharide solutions $(\Delta) ; 3 \mathrm{M}$ mono- and $1.5 \mathrm{M}$ disaccharide solutions ( $\square$ ); $4 \mathrm{M}$ mono- and $2 \mathrm{M}$ disaccharide solutions $(\diamond)$; and the control with only water $(\times)$. Error bars are 1 standard deviation and $n=3$. 

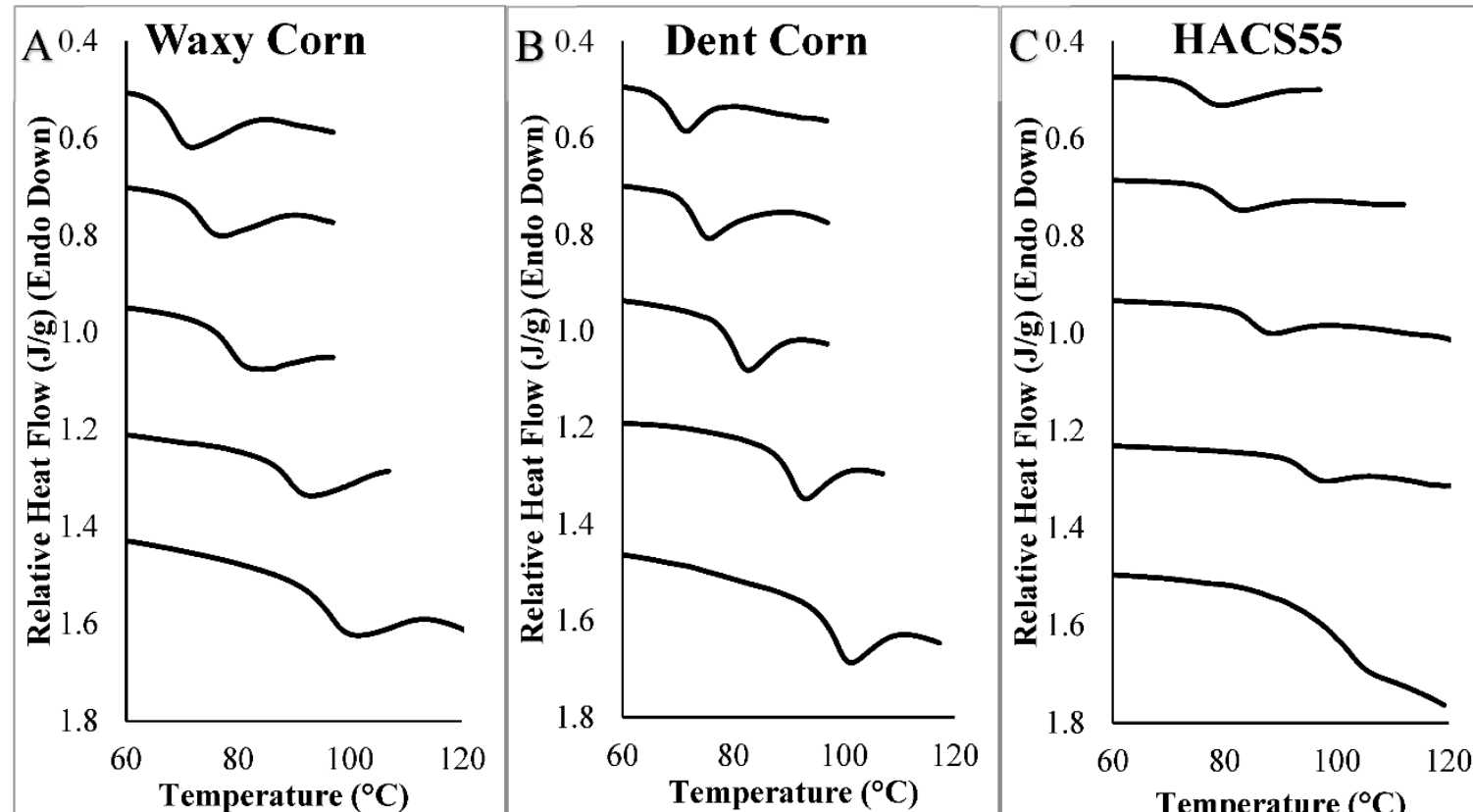

$\mathrm{D}^{0.6} \mathrm{HACS70}^{-\mathrm{HAC}^{2}}$
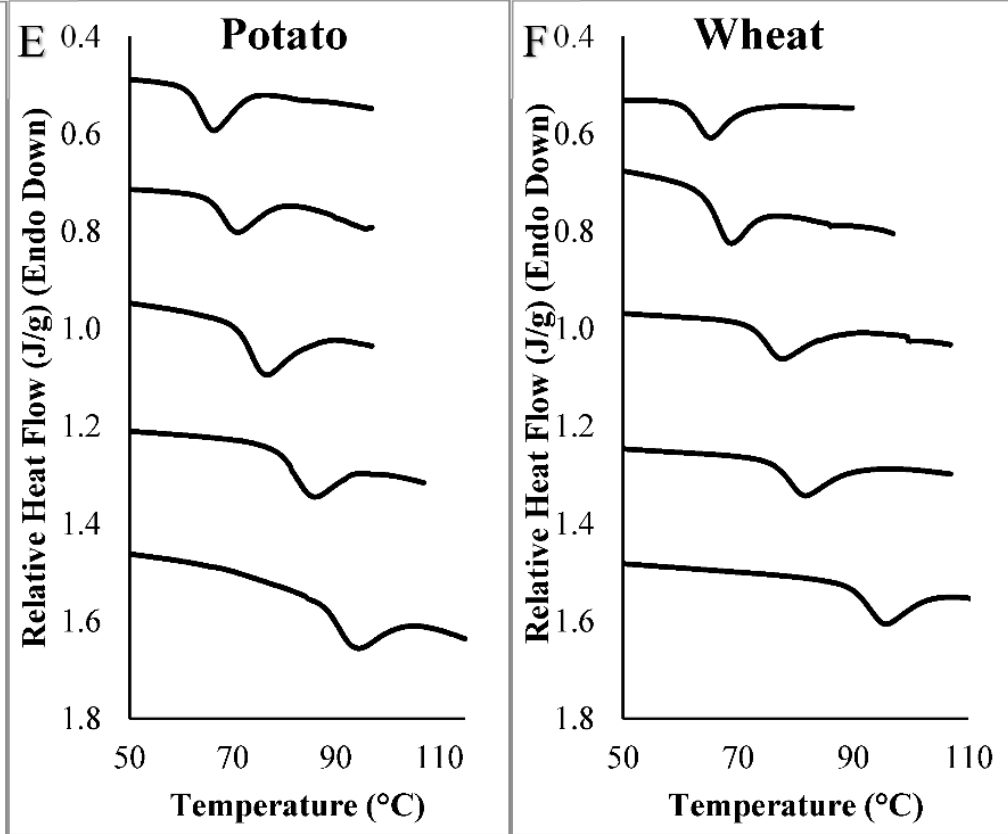

Figure 2. DSC thermograms of 1:2 w/w starch slurries in solutions containing different concentrations of sucrose: (A) waxy corn, (B) dent corn, (C) HACS55, (D) HACS70, (E) potato, and (F) wheat starch. Thermograms are shown from top to bottom from: control, $0.5 \mathrm{M}$ sucrose, $1.0 \mathrm{M}$ sucrose, $1.5 \mathrm{M}$ sucrose, and $2.0 \mathrm{M}$ sucrose.

Several sweetener properties did not positively correlate with wheat starch $\mathrm{T}_{\text {gel }}$, including $\mathrm{N}_{\mathrm{OH}, \mathrm{s}}$, $\mathrm{T}_{\mathrm{g}}$, and capacity factor $\left(K_{c}\right)$ (TableS 2 and 4). In Allan, Rajwa and Mauer [29], the direct effect of sweetener $T_{g}$ on the $T_{\text {gel }}$ was doubted due to the presence of extreme outliers and evidence the $T_{g}$ of native starch is well below the $\mathrm{T}_{\text {gel }}[7,48]$. Since $\mathrm{N}_{\mathrm{OH}, s}$ was derived from the $\mathrm{T}_{\mathrm{g}}$ of the sweetener [49], it was therefore not surprising there was no correlation of $\mathrm{T}_{\text {gel }}$ with either $\mathrm{T}_{g}$ or $\mathrm{N}_{\mathrm{OH}, s}$. However, the effective water content $\left(\varphi_{W}\right.$, eff $)$, which is directly related to volumetric density of intermolecular hydrogen bonds of the sweetener solution and calculated using $\mathrm{N}_{\mathrm{OH}, \mathrm{s}}$ [30], was still highly correlated to the starch $\mathrm{T}_{\text {gel }}$ (Figure S2). A low $K_{c}$ was associated with greater hydrophobicity in a C-18 HPLC column, but the applicability of $K_{c}$ for determining sweetener effects on starch $\mathrm{T}_{\text {gel }}$ was limited as it was not 
correlated to sweetener hydration numbers, NMR relaxation, terahertz spectroscopy, or viscosity [40]. Poor correlations between sweetener solution $\mathrm{a}_{\mathrm{w}}$ and $\mathrm{T}_{\text {gel }}$ increase have been found $[29,30]$, and there is no chemical need for water during starch gelatinization since starch can gelatinize in pure glycerol [28].

Table 3. Analyses of sweetener solution properties that influenced the $\mathrm{T}_{\text {gel }}$ onsets of waxy corn, dent corn, HACS55, HACS70, potato, and wheat starch comparisons of $p$-values from four-way ANOVA are shown. Sweetener concentrations groupings were by monomeric molar concentrations (e.g., $1 \mathrm{M}$ is $1 \mathrm{M}$ mono- and $0.5 \mathrm{M}$ disaccharide solutions), size groupings were 6- (e.g., glucose, sorbitol) and 12-carbon sweeteners (e.g., sucrose, isomalt); and reducing sugar groupings were reducing (e.g., glucose, isomaltulose) and nonreducing sweeteners (e.g., sucrose, sorbitol). Significant factors and interactions are shown in bold font $(\alpha=0.05)$.

\begin{tabular}{|c|c|c|c|c|c|c|c|}
\hline \multirow[b]{2}{*}{ Starch } & \multicolumn{7}{|c|}{$p$-Values } \\
\hline & $\begin{array}{c}\text { Sweetener } \\
\text { Concen-Tration }\end{array}$ & $\begin{array}{c}\text { Size } \\
\text { (6 OR 12-C) }\end{array}$ & $\begin{array}{c}\text { Type (Sug./Sug. } \\
\text { Alc.) }\end{array}$ & $\begin{array}{l}\text { Reducing Sugar } \\
\text { (Red./Nonred.) }\end{array}$ & $\begin{array}{l}\text { Conc.* } \\
\text { Size }\end{array}$ & $\begin{array}{l}\text { Conc.* } \\
\text { Type }\end{array}$ & $\begin{array}{l}\text { Conc.* } \\
\text { Red. }\end{array}$ \\
\hline Waxy corn & $<0.001$ & $<0.001$ & $<0.001$ & 0.981 & 0.001 & 0.060 & 0.660 \\
\hline Dent corn & $<0.001$ & $<0.001$ & $<0.001$ & 0.428 & $<0.001$ & 0.198 & 0.948 \\
\hline HACS55 & $<0.001$ & $<0.001$ & 0.004 & 0.913 & 0.070 & 0.401 & 0.358 \\
\hline HACS70 & $<0.001$ & $<0.001$ & $<0.001$ & 0.899 & 0.196 & 0.403 & 0.042 \\
\hline Potato & $<0.001$ & 0.661 & 0.003 & 0.133 & 0.911 & 0.423 & 0.671 \\
\hline Wheat & $<0.001$ & 0.001 & 0.118 & 0.513 & $<0.001$ & 0.302 & 0.005 \\
\hline
\end{tabular}

*: A standard for referring to interaction effects between the terms.

Table 4. Comparisons of correlation coefficients $(\mathrm{R})$ of slopes of $\log \mathrm{T}_{\text {gel }}$ vs. sweetener concentration (abbreviated $\log \mathrm{T}_{\text {gel }}$ in table) and $\Delta \mathrm{T}_{\text {gel }(i-0) \mathrm{S}}$ in solutions of $3 \mathrm{M}$ monosaccharide unit concentrations (3 M 6-C and 1.5 M 12-C sweetener solutions) (abbreviated $\Delta \mathrm{T}_{\text {gel(3M-0) }}$ in table) of a starch in respect to the following sweetener solution properties: the number of $\mathrm{OH}$ groups for intermolecular $\mathrm{H}$-bonding $\left(\mathrm{N}_{\mathrm{OH}, \mathrm{S}}\right)$ on the sweetener, calculated average number of equatorial and exocyclic hydroxyl groups on the sweetener in solution, dry glass transition temperature of the sweetener, sweetener solute molar volume, and sweetener capacity factor $\left(K_{\mathrm{c}}\right)$.

\begin{tabular}{|c|c|c|c|c|c|c|c|c|c|c|}
\hline \multirow[b]{3}{*}{ Starch } & \multicolumn{10}{|c|}{ Correlation Coefficients (R) } \\
\hline & \multicolumn{2}{|c|}{$\mathbf{N}_{\mathrm{OH}, \mathrm{s}}$} & \multicolumn{2}{|c|}{$\begin{array}{l}\text { Equatorial and } \\
\text { Exocyclic OHs }\end{array}$} & \multicolumn{2}{|c|}{ Dry $\mathrm{T}_{\mathrm{g}}\left({ }^{\circ} \mathrm{C}\right)$} & \multicolumn{2}{|c|}{$\begin{array}{l}\text { Molar Volume } \\
\left(\mathrm{cm}^{3} / \mathrm{mol}\right)\end{array}$} & \multicolumn{2}{|c|}{$\begin{array}{c}\text { Capacity Factor } \\
\left(K_{c}\right)\end{array}$} \\
\hline & $\begin{array}{c}\log \\
T_{\text {gel }} S\end{array}$ & $\Delta \mathrm{T}_{\text {gel(3M-0) }}$ & $\log \mathrm{T}_{\mathrm{gel} \mathrm{S}}$ & $\Delta \mathrm{T}_{\text {gel(3M-0) }}$ & $\begin{array}{c}\log \\
T_{\text {gel }} S\end{array}$ & $\Delta \mathrm{T}_{\text {gel(3M-0) }}$ & $\log \mathrm{T}_{\mathrm{gel}} \mathrm{S}$ & $\Delta \mathrm{T}_{\text {gel(3M-0) }}$ & $\begin{array}{c}\log \\
\mathrm{T}_{\text {gel }} \mathrm{S}\end{array}$ & $\Delta \mathrm{T}_{\text {gel(3M-0) }}$ \\
\hline Waxy & 0.087 & 0.260 & $0.747^{* *}$ & $0.771^{* *}$ & 0.296 & 0.506 & $0.589 *$ & $0.767^{* *}$ & 0.385 & 0.099 \\
\hline Dent corn & 0.188 & 0.342 & $0.755^{* *}$ & $0.780^{* *}$ & 0.379 & $0.563 *$ & $0.703^{* *}$ & $0.812 * *$ & 0.084 & 0.389 \\
\hline HACS55 & 0.094 & 0.294 & 0.558 * & $0.649^{* *}$ & 0.321 & 0.543 & 0.444 & $0.605^{*}$ & 0.409 & 0.087 \\
\hline HACS70 & 0.075 & 0.145 & $0.662 * *$ & $0.743^{* *}$ & 0.306 & 0.358 & $0.599 *$ & $0.618 *$ & 0.522 & 0.310 \\
\hline Potato & 0.361 & 0.039 & 0.024 & 0.159 & 0.164 & 0.197 & 0.340 & 0.077 & 0.066 & 0.321 \\
\hline Wheat & 0.074 & 0.204 & $0.606^{* *}$ & $0.676^{* *}$ & 0.315 & 0.419 & $0.623 *$ & $0.770^{* *}$ & 0.272 & 0.122 \\
\hline
\end{tabular}

${ }^{*} p$ values were $<0.10 ;{ }^{* *} p$-values were $<0.05$

\subsubsection{Waxy, Dent, and High Amylose Corn Starches}

As was found for wheat starch $\mathrm{T}_{\text {gel }}$, increasing sweetener concentrations also significantly increased the $T_{\text {gel }}$ of corn starches (Figure 1), with differences found between sweetener types. For example, at $3 \mathrm{M}$ monosaccharide unit concentration, isomalt increased the $\mathrm{T}_{\text {gel }}$ of corn starches the most and fructose increased the $T_{\text {gel }}$ the least (Tables S3-S6). Significant differences were also found between corn starch types (Figures 3 and 4 ), with dent corn starch generally exhibiting the greatest $T_{\text {gel }}$ increase $\left(\Delta \mathrm{T}_{\text {gel }(i-0))}\right)$ in the presence of sweeteners compared to the other corn starches. Exceptions were the $\Delta \mathrm{T}_{\text {gel }(i-0)} \mathrm{S}$ of waxy corn in 3 and $4 \mathrm{M}$ mannose solutions and HACS70 in $2 \mathrm{M}$ sucrose solutions, which were greater than the $\Delta \mathrm{T}_{\text {gel }(i-0)} \mathrm{S}$ of dent corn (Figures 3 and 4 ). The HACS70 $\mathrm{T}_{\text {gel }}$ in $2 \mathrm{M}$ sucrose solution was exceptionally high, likely due to the unique shape of the thermogram (Figure 2). The substantial shift in the baseline for this sample may be the onset of amylopectin hydrate dehydration or a $\mathrm{T}_{\mathrm{g}}$ event. 

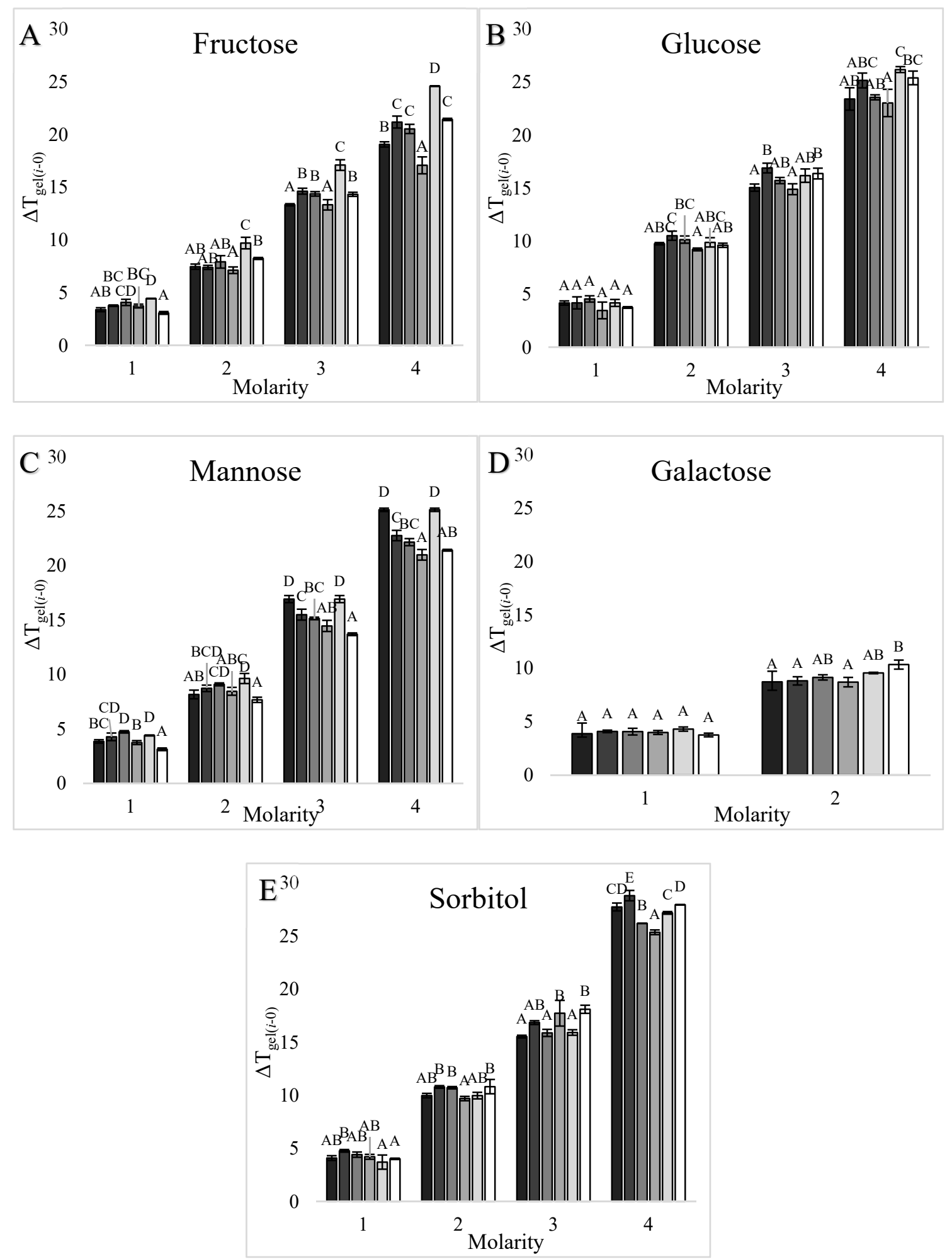

Figure 3. Effects of increasing concentrations (1-4 M) of 6-carbon sweeteners in solution on the onset $\mathrm{T}_{\text {gel }}$ of different types of starch: (A) fructose, (B) glucose, (C) mannose, (D) galactose, and (E) sorbitol. Starch from left to right as waxy corn $(\square)$, dent corn $(\square), \operatorname{HACS55}(\square)$, HACS70 ( $\square$ ), potato $(\square)$, and wheat starch ( ). The increase in the onset $\mathrm{T}_{\text {gel }}$ in the sweetener solution compared to the onset $\mathrm{T}_{\text {gel }}$ in water $\left(\Delta \mathrm{T}_{\text {gel }(i-0)}\right)$ is plotted. Error bars are 1 standard deviation, $n=3$, and the capital letters indicate significant differences between $\mathrm{T}_{\text {gel }} \mathrm{s}$. 

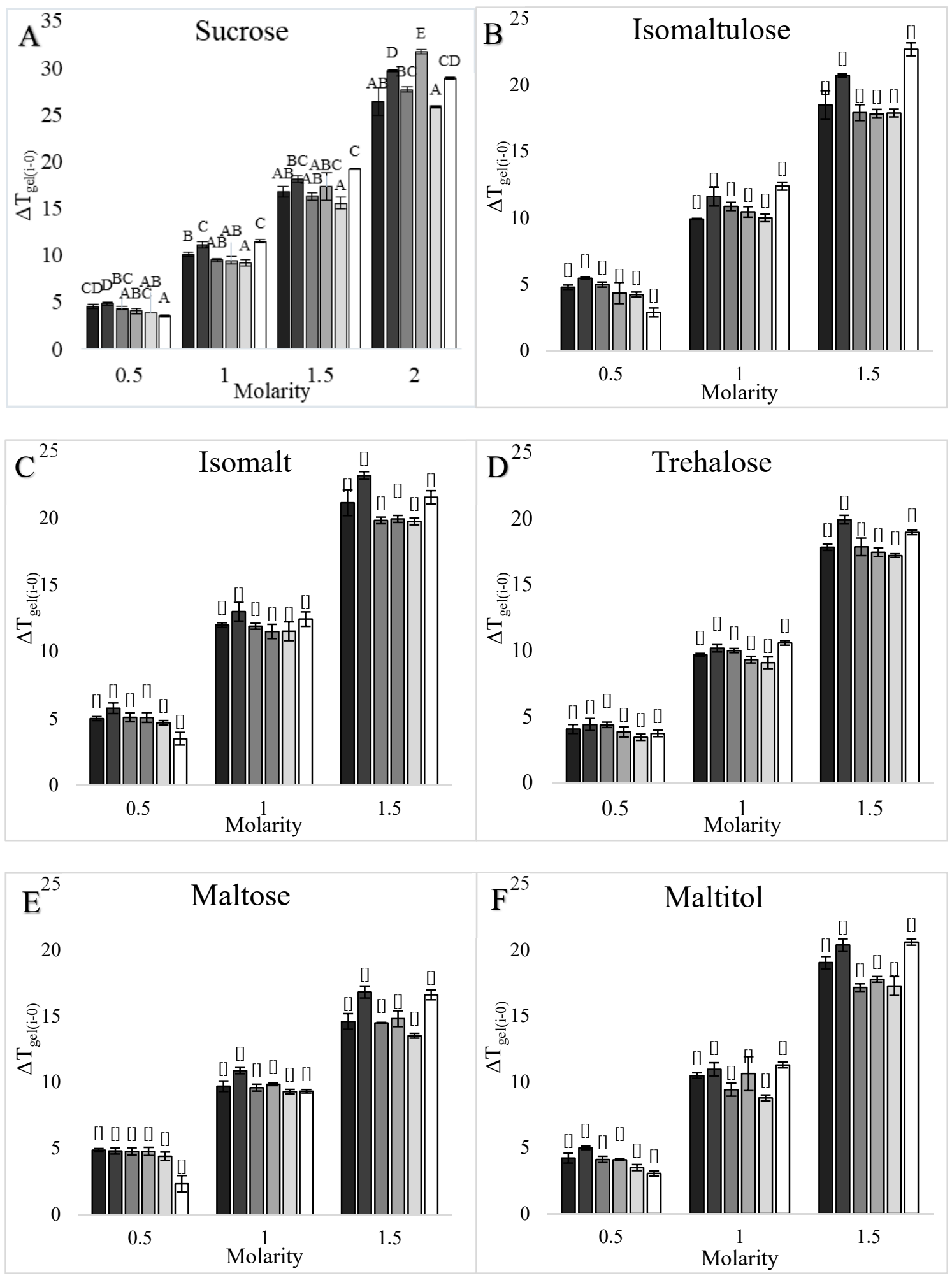

Figure 4. Effects of increasing concentrations (0.5-2.0 M) of 12-carbon sweeteners in solution on the onset $\mathrm{T}_{\text {gel }}$ of different types of starch: (A) sucrose, (B) isomaltulose, (C) isomalt, (D) trehalose,

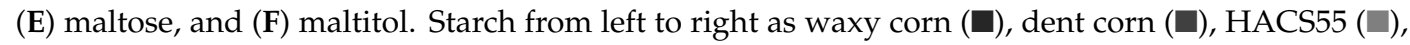
HACS70 $(\square)$, potato $(\square)$, and wheat starch $\left(\right.$ ). The increase in the onset $\mathrm{T}_{\text {gel }}$ in the sweetener solution compared to the onset $\mathrm{T}_{\text {gel }}$ in water $\left(\Delta \mathrm{T}_{\text {gel }(i-0)}\right)$ is plotted. Error bars are 1 standard deviation, $n=3$, and the capital letters indicate significant differences between $\mathrm{T}_{\text {gel }} \mathrm{s}$. 
Similar to what was found for wheat starch $\mathrm{T}_{\text {gel }} \mathrm{s}$, the categorical sweetener properties that were significantly correlated to the $\mathrm{T}_{\text {gel }} \mathrm{s}$ of all corn starches were sweetener concentration and size. A difference between corn and wheat starch behaviors was that the sweetener type (sugar or sugar alcohol) was significant for the $\mathrm{T}_{\text {gel }} \mathrm{S}$ of all corn starches but not for wheat starch $\mathrm{T}_{\text {gel }} \mathrm{S}$ (Table 3). Corn starch $\mathrm{T}_{\text {gel }} \mathrm{s}$ in 12-C sweetener solutions were generally greater than in 6-C sweetener solutions within the same monosaccharide unit concentration grouping; however, the $\mathrm{T}_{\text {gel }} \mathrm{S}$ in some $6-\mathrm{C}$ sweetener solutions, such as sorbitol, were significantly greater than in some $12-\mathrm{C}$ sweetener solutions, such as maltose (Tables S3-S6). The sweetener type (sugar or sugar alcohol) was significant for all corn starches (Table 3), with the corn starch $\mathrm{T}_{\text {gel }} \mathrm{s}$ in sugar alcohol solutions (sorbitol, isomalt, and maltitol) equal to or greater than in the counterpart sugar solutions (glucose, isomaltulose, and maltose, respectively) (Tables S3-S6). Baek, Yoo and Lim [50] also observed that corn starch $\mathrm{T}_{\text {gel }} \mathrm{S}$ in sugar alcohol solutions were greater than in sugar solutions.

The quantitative sweetener properties that were significantly correlated to the $T_{\text {gel }}$ elevation of corn starches were the numbers of equatorial and exocyclic hydroxyl groups and molar volumes $(p<0.10)$, except not the molar volume with $\log \mathrm{T}_{\text {gel }} \mathrm{S}$ of HACS55 (Table 4$)$. Similar to what was found for wheat starch $\mathrm{T}_{\text {gel }}$, the $\mathrm{N}_{\mathrm{OH}, s}, \mathrm{~T}_{\mathrm{g}}$, and $K_{c}$ of sweeteners were not significantly correlated to the sweetener effect on corn starch $T_{\text {gel }}$, while the $\varphi_{W}$, eff and solution viscosity were highly correlated to the corn starch $\mathrm{T}_{\text {gel }} \mathrm{s}$ (Figures S3-S6 and Table S2). Sweeteners that formed more H-bonds with neighboring molecules and had larger solute radii increased the $\mathrm{T}_{\text {gel }} \mathrm{s}$ of corn starches to a greater extent.

\subsubsection{Potato Starch}

Similar to wheat and corn starches, increasing sweetener concentrations increased the $\mathrm{T}_{\text {gel }}$ of potato starch; however, potato starch $\mathrm{T}_{\text {gel }}$ responded differently to some sweeteners compared to the other starches (Figure 1 and Table S7). In $3 \mathrm{M}$ monosaccharide unit concentration solutions, the highest potato starch $\mathrm{T}_{\text {gel }}$ was in a $1.5 \mathrm{M}$ isomalt solution and the lowest was in a $1.5 \mathrm{M}$ maltose solution (Table S7), which was different from the other starches for which the lowest $\mathrm{T}_{\text {gel }} \mathrm{S}$ were in $3 \mathrm{M}$ fructose solutions (Tables S1-S5). Fewer differences were found in potato starch $\mathrm{T}_{\text {gel }} \mathrm{S}$, compared to wheat and corn starches, with respect to the different effects of $6-C$ and $12-C$ sweeteners on $T_{\text {gel }}$. The 6-C sweeteners tended to elevate the $\Delta \mathrm{T}_{\text {gel }(i-0)}$ of potato starch more than $\Delta \mathrm{T}_{\text {gel }(i-0))} \mathrm{S}$ of other starches; however, the 12-C sweeteners did not elevate the $\Delta \mathrm{T}_{\operatorname{gel}(i-0)}$ of potato starch as much as the $\Delta \mathrm{T}_{\operatorname{gel}(i-0) \mathrm{s}}$ of the wheat and corn starches. Thus, the $T_{\text {gel }}$ of potato starch was one of the most affected by 6-C sweeteners (Figure 3 ) and least affected by $12-\mathrm{C}$ sweeteners (Figure 4 ) compared to the $\mathrm{T}_{\text {gel }} \mathrm{S}$ of wheat and corn starches.

Unlike for other starch types, none of the numerical sweetener factors were significantly correlated to the potato starch $\mathrm{T}_{\text {gel }}$ (Table 4); however, the number of equatorial and exocyclic hydroxyl groups and molar volumes of $6-\mathrm{C}$ sweeteners were significantly correlated with $\log \mathrm{T}_{\text {gel }} \mathrm{s}$. When correlating $\log \mathrm{T}_{\text {gel }} \mathrm{S}$ of potato starch with only $6-\mathrm{C}$ sweetener properties (excluding $12-\mathrm{C}$ sweetener properties), the correlation with the number of equatorial and exocyclic hydroxyl groups increased from $\mathrm{R}=0.024$ to $\mathrm{R}=0.996(p<0.05)$, and the correlation with the molar volume increased from $\mathrm{R}=0.340$ to $\mathrm{R}=0.945$ $(p<0.10)$. The $\log \mathrm{T}_{\text {gel }}$ of potato starch in galactose solutions was excluded from these correlations due to low galactose solubility resulting in a limited number of data points (only 1 and $2 \mathrm{M}$ ). The significant correlations of potato starch $\log \mathrm{T}_{\text {gel }}$ with 6-C sweetener molar volumes and the number of equatorial and exocyclic $\mathrm{OHs}$ suggest the mechanism by which 6-C sweeteners increased the $\mathrm{T}_{\text {gel }}$ of potato, wheat, and corn starches was similar. None of the 12-C sweetener properties were correlated with the log $\mathrm{T}_{\text {gel }} \mathrm{S}$ of potato starch, attributed to a potential size limiting effect that altered the sweetener-starch interactions of $12-\mathrm{C}$ sweeteners in the potato starch granule (discussed in detail later).

\subsection{Effects of Starch Properties}

When comparing the effects of sweeteners on the $\mathrm{T}_{\text {gels }}$ of starches from different botanical sources (Figures 3 and 4 ), significant differences in the $\Delta \mathrm{T}_{\text {gel }(i-0)}$ between starches were found. Differences 
were also found in the significant sweetener factors associated with the $\mathrm{T}_{\text {gel }} \mathrm{s}$ (Tables 3 and 4 ) of these starches. Therefore, sweeteners affected the $\mathrm{T}_{\mathrm{gel}} \mathrm{s}$ of starches from different botanical sources differently, and thus it was of interest to explore how these differences were influenced by starch composition, architecture, and morphology.

\subsubsection{Amylose Content}

The starches evaluated had varying amylose compositions ranging from $\approx 0 \%$ amylose in waxy corn starch up to $68 \%$ apparent amylose in HACS70 (Table 1). Within the corn starch sources, the effects of sweeteners on the $\Delta \mathrm{T}_{\text {gel }(i-0)} \mathrm{s}$ were not consistent with the amylose contents. For example, the dent

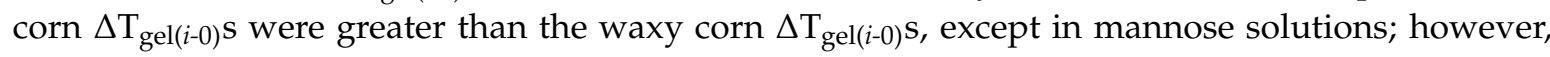
the $\Delta \mathrm{T}_{\text {gel }(i-0)} \mathrm{s}$ of HACS55 and HACS70, which contained even more amylose, were also less than dent corn (Figures 3 and 4). When evaluating all starch sources, there were no significant correlations $(p<0.10)$ between the $\Delta \mathrm{T}_{\text {gel }(3 \mathrm{M}-0)}$ or $\log \mathrm{T}_{\text {gel }} \mathrm{s}$ of a sweetener and the amylose (apparent and absolute) contents of any of the starches (Table S8).

When comparing only waxy and dent corn starches, the presence of amylose increased the $\Delta \mathrm{T}_{\text {gel }}(i-0)$ in the presence of sweeteners. The interspersed amylose in the amorphous regions of native starch may have allowed for a greater stabilization effect from sweetener H-bond bridges. However, this trend did not persist with further increases in amylose content, perhaps because additional starch structural changes were present. The high amylose corn starches have much longer amylopectin branch lengths, greater IB-CLs, and are in the B-type crystalline form; while waxy and dent corn have more comparable amylopectin structures (Table 1).

Other studies have found varying relationships between $\mathrm{T}_{\text {gel }}$ and amylose content: some studies suggest starches with greater amylose contents have higher $\mathrm{T}_{\text {gel }} \mathrm{s}$ [51,52], others report no effect on $\mathrm{T}_{\text {gel }}$ [53-56], and yet others report lower $\mathrm{T}_{\text {gel }} \mathrm{s}$ for starches with higher amylose contents [17]. It has also been proposed that the type of amylose affects the $\mathrm{T}_{\text {gel }}$ behavior: lipid complexed amylose increases the $T_{\text {gel }}$ [19]. Salts have been reported to affect the $T_{\text {gel }}$ and $\Delta H$ of gelatinization of waxy and normal corn starches in a similar manner [57], thus amylose content made little difference. Therefore, the lack of correlations between the $\mathrm{T}_{\text {gel }}$ increase in sweetener solutions and the amylose contents of starches (Table S8) suggest amylose contents did not greatly affect the sweetener-starch interactions that increase the $\mathrm{T}_{\text {gel }}$.

\subsubsection{Amylopectin Architecture}

The starches in this study had varying amylopectin architectures (Table 1). HACS55 and HACS70 had longer amylopectin chain lengths, smaller percentages of short DP 6-12 amylopectin chains, higher percentages of DP 25-36 and DP $\geq 37$ amylopectin chains, lower NBbls, and higher IB-CLs (Table 1), and the $T_{\text {gel }} \mathrm{S}$ of these starches were least affected by sweeteners (Figures 3 and 4 ). The $T_{\text {gel }} \mathrm{s}$ of wheat and dent corn starches were more affected by sweeteners (Figures 3 and 4), and these starches had shorter amylopectin chain lengths, higher ratios of DP 6-12 chains, lower percentages of DP 25-36 and $\mathrm{DP} \geq 37$ amylopectin chains, higher numbers of NBbls, and lower IB-Cls. When comparing all starches in this study, the percentages of DP $25-36$ and DP $\geq 37$ chains and the average amylopectin chain lengths of starches were negatively correlated with $\mathrm{T}_{\text {gel }}$ elevations in different sweeter solutions (Table 5). In contrast, the $\mathrm{T}_{\text {gel }}$ elevations of starches in sweetener solutions were positively correlated with higher percentages of DP 6-12 amylopectin chains (Table 5). Therefore, the $\mathrm{T}_{\text {gel }} \mathrm{S}$ of starches with higher percentages of short amylopectin chains were more affected by sweeteners than the $T_{\text {gel }} S$ of starches with longer amylopectin chains. The $\mathrm{T}_{\text {gel }}$ increases for starches in several sweetener solutions were also positively correlated with the NBbl of starches and negatively correlated with IB-CLs of starches (Table 6), suggesting that amylopectin fine structure also influenced the sweetener-starch interactions. 
Table 5. Comparisons of correlation coefficients (R) of slopes of $\log \mathrm{T}_{\text {gel }}$ vs. sweetener concentration (abbreviated $\log \mathrm{T}_{\text {gel }}$ in table) and $\Delta \mathrm{T}_{\text {gel }(i-0)} \mathrm{S}$ in solutions of $3 \mathrm{M}$ monosaccharide unit concentrations ( $3 \mathrm{M}$ 6-C and $1.5 \mathrm{M} 12-\mathrm{C}$ sweetener solutions) (abbreviated $\Delta \mathrm{T}_{\text {gel }(3 \mathrm{M}-0)}$ in table) of a sweetener in respect to average amylopectin chain length, percentage of DP 6-12 chains, percentage of DP 13-24 chains, percentage of DP 25-36, and percentage of DP $\geq 37$ chains.

\begin{tabular}{|c|c|c|c|c|c|c|c|c|c|c|}
\hline \multirow[b]{3}{*}{ Sugar } & \multicolumn{10}{|c|}{ Correlation Coefficients (R) } \\
\hline & \multicolumn{2}{|c|}{ Average Chain Length } & \multicolumn{2}{|c|}{$\%$ DP 6-12 } & \multicolumn{2}{|c|}{ \% DP 13-24 } & \multicolumn{2}{|c|}{ \% DP 25-36 } & \multicolumn{2}{|c|}{$\% \mathrm{DP} \geq 37$} \\
\hline & $\log \mathrm{T}_{\mathrm{gel}}$ & $\Delta \mathrm{T}_{\text {gel(3M-0) }}$ & $\log \mathrm{T}_{\mathrm{gel}}$ & $\Delta \mathrm{T}_{\text {gel(3M-0) }}$ & $\log \mathrm{T}_{\mathrm{gel}}$ & $\Delta \mathrm{T}_{\text {gel(3M-0) }}$ & $\log \mathrm{T}_{\mathrm{gel}}$ & $\Delta \mathrm{T}_{\text {gel(3M-0) }}$ & $\log \mathrm{T}_{\text {gel }}$ & $\Delta \mathrm{T}_{\text {gel(3M-0) }}$ \\
\hline Fructose & -0.145 & 0.261 & 0.35 & -0.043 & -0.049 & -0.143 & $-0.764 *$ & -0.527 & -0.078 & 0.341 \\
\hline Galactose & $-0.734 *$ & NA & $0.747 *$ & NA & -0.174 & NA & -0.633 & NA & $-0.813 *$ & NA \\
\hline Glucose & -0.454 & -0.385 & 0.649 & 0.547 & 0.048 & 0.107 & $-0.900 * *$ & $-0.751^{*}$ & -0.394 & -0.321 \\
\hline Isomalt & $-0.774^{*}$ & -0.773 * & $0.914^{* *}$ & $0.820^{* *}$ & 0.365 & 0.551 & $-0.933 * *$ & -0.633 & -0.702 & -0.708 \\
\hline Isomaltulose & $-0.746^{*}$ & $-0.778 *$ & $0.842 * *$ & $0.808^{*}$ & 0.007 & -0.016 & $-0.741 *$ & -0.541 & $-0.748 *$ & $-0.810^{* *}$ \\
\hline Maltitol & $-0.857^{* *}$ & $-0.886^{* *}$ & $0.938^{* *}$ & $0.904^{* *}$ & 0.220 & 0.311 & $-0.761 *$ & -0.589 & $-0.838^{* *}$ & $-0.877^{* *}$ \\
\hline Maltose & $-0.758^{*}$ & -0.677 & $0.881^{* *}$ & 0.674 & 0.266 & 0.114 & -0.820 ** & -0.343 & -0.707 & -0.695 \\
\hline Mannose & -0.025 & 0.498 & 0.255 & -0.302 & 0.057 & 0.066 & $-0.761 *$ & -0.318 & 0.076 & 0.616 \\
\hline Sorbitol & -0.674 & -0.111 & $0.822 * *$ & 0.137 & 0.075 & -0.631 & $-0.873^{* *}$ & 0.104 & -0.640 & -0.207 \\
\hline Sucrose & -0.628 & -0.649 & 0.728 & 0.623 & -0.146 & -0.110 & -0.567 & -0.210 & -0.646 & -0.711 \\
\hline Trehalose & $-0.787^{*}$ & -0.687 & $0.894^{* *}$ & 0.718 & 0.188 & 0.345 & -0.840 * & -0.521 & $-0.756^{*}$ & -0.655 \\
\hline
\end{tabular}


Table 6. Comparisons of correlation coefficients (R) of slopes of $\log \mathrm{T}_{\text {gel }}$ vs. sweetener concentration (abbreviated $\log \mathrm{T}_{\text {gel }}$ in table) and $\Delta \mathrm{T}_{\text {gel }(i-0)} \mathrm{S}$ in solutions of $3 \mathrm{M}$ monosaccharide unit concentrations (3 M 6-C and 1.5 M 12-C sweetener solutions) (abbreviated $\Delta \mathrm{T}_{\text {gel }(3 \mathrm{M}-0)}$ in table) of a sweetener in respect to the number of building blocks per cluster (NBbl), and inter-block chain length (IB-CL).

\begin{tabular}{ccccc}
\hline & \multicolumn{4}{c}{ Correlation Coefficients (R) } \\
\cline { 2 - 5 } NBbl & \multicolumn{2}{c}{ IB-CL } \\
\cline { 2 - 5 } Sugar & $\log \mathbf{T}_{\text {gel }}$ & $\Delta \mathrm{T}_{\text {gel(3M-0) }}$ & $\log \mathbf{T}_{\text {gel }}$ & $\Delta_{\text {gel(3M-0) }}$ \\
\hline Fructose & -0.451 & -0.65 & -0.405 & -0.026 \\
Galactose & 0.717 & NA & -0.613 & NA \\
Glucose & -0.116 & 0.247 & -0.65 & -0.369 \\
Isomalt & 0.302 & 0.674 & $-0.856^{* *}$ & -0.675 \\
Isomaltulose & 0.447 & 0.709 & -0.717 & -0.619 \\
Maltitol & 0.504 & $0.742^{*}$ & $-0.863^{* *}$ & $-0.769 *$ \\
Maltose & 0.509 & $0.918^{* *}$ & $-0.765^{*}$ & -0.434 \\
Mannose & -0.572 & -0.715 & -0.356 & 0.207 \\
Sorbitol & 0.163 & 0.651 & $-0.792 *$ & 0.011 \\
Sucrose & 0.587 & $0.897^{* *}$ & -0.609 & -0.427 \\
Trehalose & 0.413 & $0.786^{*}$ & $-0.774 *$ & -0.482 \\
\hline & ${ }^{*} p$ values were $<0.10 ; * * p$-values were $<0.05$ &
\end{tabular}

The architecture of amylopectin has been associated with the thermal properties of starch, attributed to the stability of the starch crystallites $[14,15,19,20,55,58-60]$. Starches with higher ratios of short amylopectin chains tend to have lower $\mathrm{T}_{\text {gel }} \mathrm{s}$ because these short chains are too short to crystallize and also act as crystal defects $[15,19,20]$. Therefore, the starches with higher percentages of DP 6-12 amylopectin chains (e.g., dent corn and wheat starches were 17.9 and 19.0\% DP 6-12, respectively) have less stable starch crystallites, and sweeteners presumably formed sweetener-starch interactions that enhanced the crystallite stability and resulted in a greater $T_{\text {gel }}$ elevation. Starches with smaller ratios of DP 6-12 amylopectin branches (e.g., HACS55 and HACS70 were 9.7 and 8.5\% DP 6-12, respectively) had $\mathrm{T}_{\text {gel }} \mathrm{s}$ that were less affected by sweeteners because there were fewer crystal defects. The negative linear correlations between $\mathrm{T}_{\text {gel }}$ increases in sweetener solutions and average amylopectin chain lengths, percentages of DP $25-36$, and percentages of DP $\geq 37$ (Table 5) suggest the $\mathrm{T}_{\text {gel }} \mathrm{s}$ of starches with longer amylopectin branches are less affected by sweetener solutions. The DP 6-12, 13-24, $25-36$, and $\geq 37$ amylopectin chains fractions have been defined as $\mathrm{A}(\mathrm{fa}), \mathrm{B} 1\left(\mathrm{fb} \mathrm{b}_{1}\right), \mathrm{B} 2\left(\mathrm{fb}_{2}\right)$, and B3 $\left(\mathrm{fb}_{3}\right)$ chains and span through 1, 1,2, and 3 crystalline amylopectin clusters, respectively [61,62]. The B2 (DP 25-36) and B3 (DP $\geq 37$ ) amylopectin branches span through multiple clusters and are long enough to make relatively defect-free crystallites. Crystallites that have fewer crystal defects and are covalently linked to one another are already fairly stable, thus sweeteners in solution have a lower potential for elevating the $T_{\text {gel }}$ because there are fewer possibilities for stabilizing sweetener-starch intermolecular interactions. There were also no significant correlations between $T_{\text {gel }}$ increases in sweetener solutions and percentages of B1 (DP 13-24) chains, which could be due to the intermediate length between stabilizing and destabilizing amylopectin chain lengths.

The fine structure of amylopectin also affects the $\mathrm{T}_{\text {gel }}$, with lower $\mathrm{NBbl}$ and higher IB-CL values associated with higher $\mathrm{T}_{\text {gel }} \mathrm{s}$ [11]. There were significant correlations with NBbl and IB-CL of starches and the effects of sweeteners increasing the $\mathrm{T}_{\text {gel }} \mathrm{s}$ (Table 6). With fewer building blocks in a cluster $(\mathrm{NBbl})$ and greater spacing between building blocks (IB-CL) allowing for more molecular flexibility, the double helices in the crystalline amylopectin clusters are able to form more hydrogen bonds and a stronger crystal structure [11]. Therefore, native starches with more blocks per cluster and shorter spacing between building blocks have less stable crystallites, and thus sweetener-starch interactions have a greater stabilizing effect (Table 5). For example, the $\mathrm{T}_{\text {gel }} \mathrm{S}$ of wheat and dent corn starches increased the most in sweetener solutions (Figures 3 and 4) and these starches had the greatest number of building blocks per cluster (NBbl) and shorter IB-CLs (Table 1). In contrast, the $\mathrm{T}_{\text {gel }} \mathrm{s}$ of high amylose 
corn starches had the smallest $\mathrm{T}_{\text {gel }}$ increases in sweetener solutions (Figures 3 and 4 ) and had the highest IB-CLs and lower NBbl values. Again, the $\mathrm{T}_{\text {gel }} \mathrm{s}$ of starches with more stable crystals were less affected by sweeteners.

Also of note, sweeteners that increased the $\mathrm{T}_{\text {gel }}$ the most (isomalt, maltitol, and isomaltulose (Figure 1)) tended to have the strongest correlations between $\mathrm{T}_{\text {gel }}$ increase and amylopectin lengths, NBb1, and IB-CL (Tables 5 and 6). It was postulated this occurred because these sweeteners had the greatest stabilizing effect due to the larger molar volumes and higher numbers of equatorial and exocyclic hydroxyl groups (Table 2), and starches with the greatest potential for sweetener-starch stabilizing interactions had $\mathrm{T}_{\text {gel }} \mathrm{s}$ that were more affected by these sweeteners.

In summary, amylopectin structure affected the extent to which sweeteners increased the $\mathrm{T}_{\text {gel }}$. The $\mathrm{T}_{\text {gel }} \mathrm{S}$ of starches that had less stable crystallites, due to shorter amylopectin chain lengths and sterically hindered double helical clusters, were more affected in sweetener solutions than starches with more stable crystalline regions. Since sweetener-starch interactions drive the $\mathrm{T}_{\text {gel }}$ increase, starches that have more regions to be stabilized (e.g., wheat and dent corn starches as shown in Tables 5 and 6) had greater $\mathrm{T}_{\text {gel }}$ increases in the presence of sweetener solutions.

\subsubsection{Amylopectin Crystalline Structure}

Starches with A-type and B-type amylopectin crystalline structures were used in this study: waxy corn, dent corn, and wheat starch were the A-type polymorphic form while HACS55, HACS70, and potato starches were the B-type polymorphic form (Table 1). The $\mathrm{T}_{\text {gel }} \mathrm{S}$ of A-type starches increased more in sweetener solutions than the $\mathrm{T}_{\text {gel }} \mathrm{s}$ of B-type starches (Table S9) based on comparing the averages of $\log \mathrm{T}_{\text {gel }} \mathrm{S}$ and the $\Delta \mathrm{T}_{\text {gel }(3 \mathrm{M}-0)} \mathrm{S}$ in $\mathrm{A}$ and B-type starches. However, the $\Delta \mathrm{T}_{\text {gel }(i-0) \mathrm{S}} \mathrm{s}$ dent corn (A-type), wheat (A-type), and potato in 6-C solutions (B-type) starches were the most affected by sweeteners, while the $\Delta \mathrm{T}_{\text {gel }(i-0)} \mathrm{s}$ of waxy (A-type), potato (B-type) in 12-C solutions, and high amylose corn starches (B-type) were the least affected (Figures 3 and 4). Thus, there did not appear to be a consistent trend in $\Delta \mathrm{T}_{\text {gel }(i-0)}$ response to sweeteners in solution based solely on amylopectin crystal polymorph. A confounding factor was likely that starches with longer amylopectin chains form B-type crystal structures (Table 1 ) and the $\mathrm{T}_{\text {gel }} \mathrm{S}$ of starches with longer amylopectin branches were less affected by sweeteners (e.g., high amylose corn starches in Figures 3 and 4). In theory, the crystalline form should not affect the influence of sweeteners on $T_{\text {gel }}$, because sweeteners increase the $T_{\text {gel }}$ through intermolecular interactions in the amorphous regions of starch [29].

\subsubsection{Percent Crystallinity}

No correlation was found between the percent crystallinity of starches and the effects of sweeteners on the $\mathrm{T}_{\text {gel }}$ increase (Table S8). For example, the high amylose corn and wheat starches were all $\sim 20 \%$ crystalline, yet the $T_{\text {gel }}$ of wheat starch was more influenced by sweeteners than the $T_{\text {gels }}$ of the high amylose corn starches (Figures 3 and 4). Even though the sweetener-starch interactions that stabilize the granule and increase the $T_{\text {gel }}$ occur in the amorphous regions [29], perhaps the amount or distribution of the amorphous regions were not limiting factors within this experimental space, since the native starches in this study were all $>50 \%$ amorphous.

\subsubsection{Potato Starch—The Anomaly}

There were similar sweetener effects on $\Delta \mathrm{T}_{\text {gel }(i-0)}$ trends between starches from different botanical sources (Figures 3 and 4 ) with few exceptions other than for potato starch. Potato starch was also the only starch that had a $\mathrm{T}_{\text {gel }}$ not affected by the sweetener size (Table 2), since potato starch $\mathrm{T}_{\text {gel }} \mathrm{s}$ in 6-C sweetener solutions were not significantly different from $\mathrm{T}_{\text {gel }} \mathrm{s}$ in $12-\mathrm{C}$ sweetener solutions. It has been reported that $12-\mathrm{C}$ sweeteners (disaccharides) increase the $\mathrm{T}_{\text {gel }}$ of starch more than $6-\mathrm{C}$ sweeteners (monosaccharides) for other starch botanical sources $[22,29,50]$. Therefore, the unique aspects of potato starch were explored to elucidate why the sweetener effects on the $T_{\text {gel }}$ elevation behavior of potato starch were different than for other starches. 


\section{(1) Size Exclusion within the Granule}

A speculation as to why $12-\mathrm{C}$ sweeteners were not as effective at raising the $\mathrm{T}_{\text {gel }}$ of potato starch compared to elevating the $T_{\text {gel }} \mathrm{s}$ of starches from other botanical sources was due to some sort of size exclusion, wherein the diffusion of $12-\mathrm{C}$ sweeteners throughout the potato starch granule was affected differently than diffusion in other starch types. The molecular size exclusion could be due to: (1) the spacing of amylopectin branch points, and/or (2) the spacing between blocklets in the crystalline growth rings. In potato starch, the amylopectin branch length from the backbone to the crystalline double helix is $\sim 3$ glucosyl units long, much shorter than for waxy rice, tapioca, and wheat starches that have branch lengths of 6, 7, and 7 glucosyl units long, respectively [63]. This short distance between the backbone to the crystalline helix in potato starch creates a smaller region for sweetener-starch interactions in the amorphous lamella, which potentially creates steric hindrance or spatial challenges for a DP 2 sweetener in a space that is $\sim$ DP 3 in size. This amylopectin branch length between the backbone and double helix is not to be confused with amylopectin lamella spacing, which is consistently $\sim 9 \mathrm{~nm}$ between starch sources [5]. Another possible size exclusion point is the space between the crystalline blocklets in the crystalline growth rings. The blocklets in potato starch are much larger $(200-500 \mathrm{~nm})$ than the blocklets in wheat starch $(80-120 \mathrm{~nm})$, which reduces the porosity of potato starch $[6,64]$. This lower porosity in the crystalline growth ring may restrict the diffusion of $12-\mathrm{C}$ sweeteners and thus affect the localized concentration of sweetener solutions in the amorphous regions of potato starch.

\section{(2) Phosphorous Content}

Another unique aspect of potato starch is that it contains phosphate monoesters. The phosphate monoesters cause potato starch to be affected by electrolytes [65] and have a lower $\mathrm{T}_{\text {gel }}$ compared to other starches with similar amylopectin structures, because the crystallites are destabilized when the phosphate groups repel from each other during heating $[64,66]$. The phosphate groups are predominantly (74-78\%) in the amorphous regions [67]; however, phosphate content has been both positively correlated [67] and not correlated $[20,56]$ to the potato starch $\mathrm{T}_{\text {gel }}$. It is important to note that the positive correlation of phosphate content and $\mathrm{T}_{\text {gel }}$ could have been confounded with the effects of longer amylopectin chains [67], which also elevate $\mathrm{T}_{\text {gel }}$. Since phosphates are ionizable groups, it was assumed the $\mathrm{p} K_{\mathrm{a}} \mathrm{s}$ of potato starch were similar to the $\mathrm{p} K_{\mathrm{a}} \mathrm{s}$ of phosphoric acid: there would be no $\mathrm{p} K_{\mathrm{a} 3}$ at 12.67 due to the ester linkage with starch, $\mathrm{p} K_{\mathrm{a} 1}$ at 2.21, and $\mathrm{p} K_{\mathrm{a} 2}$ at 7.21 ( $\mathrm{p} K_{\mathrm{a}}$ values from Weast [68]). A similar assumption was made by Marsh and Waight [69], but the $\mathrm{p} K_{\mathrm{a}} \mathrm{s}$ of potato starch have also been assumed to be similar to those of glucose 6-phosphate at $\mathrm{p} K_{\mathrm{a} 1} \approx 0.94$ and $\mathrm{p} K_{\mathrm{a} 2} \approx 6.11[70,71]$. Regardless, the $\mathrm{T}_{\text {gel }} \mathrm{s}$ of potato starch in $1 \mathrm{M}$ glucose solutions with $\mathrm{pHs}$ ranging from 4 to 10 were the same, at $\sim 65^{\circ} \mathrm{C}$ (Figure 5). The lack of $\mathrm{T}_{\text {gel }}$ changes at $\mathrm{pHs}$ above and below $\mathrm{pK} \mathrm{a}_{\mathrm{a}}$ in the presence of a sweetener suggests that the phosphate monoesters do not influence the sweetener-starch interactions to an extent that would affect the $\mathrm{T}_{\text {gel }}$. The phosphate monoesters may not affect sweetener-starch interactions because there is a relatively low concentration of phosphate groups: one per $\sim 317$ glucosyl units [72]. Another explanation could be that the phosphate monoesters are primarily located on long $B$ chains that are greater than DP 20 [72], and DP > 18 amylopectin branches are the stabilizing portions in potato starch since they yield more stable crystals and higher $\mathrm{T}_{\text {gel }} \mathrm{s}$ [20]. The $\mathrm{T}_{\text {gel }}$ of yam starch, which has about one-seventh of the amount of phosphate monoesters compared to potato starch [73], was also unaffected by changes in $\mathrm{pH}$ [74].

Therefore, the most likely reason potato starch $\mathrm{T}_{\text {gel }} \mathrm{s}$ exhibited different trends in the presence of 12-C sweeteners compared to $\mathrm{T}_{\text {gel }} \mathrm{S}$ of starches from other botanical sources is that the sweetener diffusion throughout the amorphous regions of the potato starch granule was restricted more than in other starch types, thereby limiting the amount of $12-\mathrm{C}$ sweetener-starch interactions in native potato starch. 


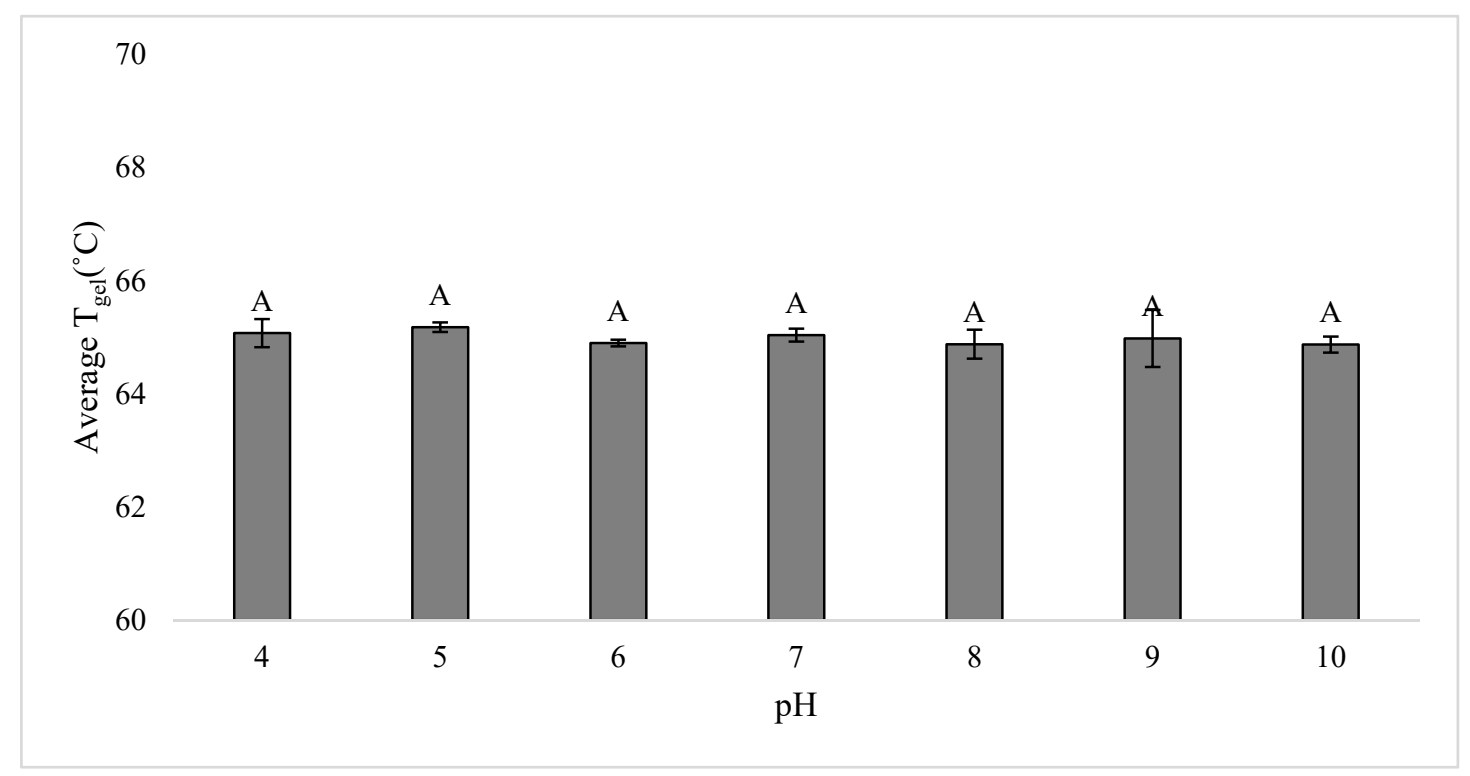

Figure 5. The onset $\mathrm{T}_{\text {gel }} \mathrm{S}$ of potato starch in $1 \mathrm{M}$ glucose solutions at $\mathrm{pHs} 4,5,6,7,8$, 9, and 10 . Error bars are 1 standard deviation, $n=3$, and the capital letters indicate significant differences in $\mathrm{T}_{\text {gel }} \mathrm{s}$.

\section{Conclusions}

The effects of 6-C and 12-C sweeteners on the $\mathrm{T}_{\text {gel }} \mathrm{s}$ of six different starches were investigated. The $\mathrm{T}_{\text {gel }} \mathrm{s}$ of all starches increased in sweetener solutions compared to $\mathrm{T}_{\text {gel }} \mathrm{s}$ in water, with greater $\mathrm{T}_{\text {gel }}$ increases as sweetener concentration increased; however, the magnitude of the increase in $T_{\text {gel }}$ varied between different types of sweeteners and starches. The starch $\mathrm{T}_{\text {gel }}$ was increased more by sweeteners that had larger molar volumes and higher numbers of equatorial and exocyclic hydroxyl groups (e.g., sugar alcohols and 12-C sweeteners). Sweeteners with these properties formed more sweetener-starch interactions, stabilizing the amorphous starch regions, and thereby increased the $\mathrm{T}_{\text {gel }}$ to a greater extent. Sweetener traits that were not associated with increases in starch $\mathrm{T}_{\text {gel }}$ were: dry $\mathrm{T}_{\mathrm{g}}, \mathrm{K}_{c}, \mathrm{~N}_{\mathrm{OH}, \mathrm{s}}$, and whether or not the sweetener was a reducing sugar. The amylopectin structure of starches also affected the $T_{\text {gel }}$ increase in sweetener solutions. The $T_{\text {gel }} \mathrm{s}$ of starches with higher percentages of A-chains (DP 6-12) increased the most in sweetener solutions, whereas the $\mathrm{T}_{\text {gel }} \mathrm{S}$ of starches with higher percentages of B2 (DP 25-36) and B3 (DP $\geq 37$ ) amylopectin chains increased less in sweetener solutions. The amylopectin fine structure also influenced the effects of sweetener solutions on the $\mathrm{T}_{\mathrm{gel}}$, where starches with fewer building blocks per cluster and longer inter-block chain lengths formed more stable crystals and the $T_{\text {gel }} \mathrm{S}$ were less affected. A-type starches were more affected by sweeteners than B-type starches, but this may be confounded with B-type starches having longer amylopectin chains. Starch traits that were not associated with $\mathrm{T}_{\text {gel }}$ increases in the presence of sweeteners included: amylose content and percent crystallinity. The effects of sweeteners on the $T_{\text {gel }}$ elevation of potato starch were unique, because the potato starch $T_{\text {gel }}$ was one of the most affected by $6-\mathrm{C}$ sweeteners and the least affected by $12-\mathrm{C}$ sweeteners. This was attributed to a size exclusion phenomenon that altered $12-\mathrm{C}$ sweetener diffusion into the potato starch granules and was not due to ionic effects of the phosphate monoesters. In summary, starches with less stable crystalline regions are more susceptible to sweetener-starch stabilizing effects and exhibited greater increases in $T_{\text {gel }}$ in the presence of sweeteners. Native starches with structures that limit sweetener-starch interactions, such as the more stable crystalline regions in high-amylose corn starches or the unique structures in potato starch that limit diffusion of $12-\mathrm{C}$ sweeteners, exhibit smaller increases in $\mathrm{T}_{\text {gel }}$. However, sweeteners with molecular conformations that were favorable for intermolecular interactions increased the $\mathrm{T}_{\text {gel }}$ the most, regardless of starch architecture. This study has shown the different $\mathrm{T}_{\text {gel }}$ elevation effects of sweeteners on multiple starch botanical sources and provided insights into structural reasons 
for these differences, information that is useful for improving the understanding of structure-function relationships and behaviors of starches in formulations containing different sweeteners.

Supplementary Materials: The following are available online at http://www.mdpi.com/2304-8158/9/6/757/s1, Figure S1: DSC thermograms of starch slurries $(1: 2 w / w)$ in water and the measured onset temperature, peak temperature, and $\Delta \mathrm{H}$ of gelatinization, Table S1: The onset $\mathrm{T}_{\text {gel }} \mathrm{S}$ of wheat starch in sweetener solutions grouped by similar solution solids content (same monomeric unit concentration) as follows: Group 1 contains $1 \mathrm{M}$ mono-, $0.5 \mathrm{M}$ disaccharide solutions; Group 2 contains $2 \mathrm{M}$ mono-, $1 \mathrm{M}$ disaccharide solutions; Group 3 contains $3 \mathrm{M}$ mono- and $1.5 \mathrm{M}$ disaccharide solutions; and Group 4 contains $4 \mathrm{M}$ mono- and $2 \mathrm{M}$ disaccharide, Table S2: Pearson correlation coefficients $(r)$ and P-values of $\mathrm{T}_{\text {gel }} \mathrm{s}$ and sweetener solution viscosities (log(centipoise)). Solution viscosities were from Allan and others (2018), Figure S2: Wheat starch $\mathrm{T}_{\text {gel }}$ onsets in sweetener solutions in respect to the effective water content $\left(\varphi_{W}\right.$, eff) reported in van der Sman and Mauer (2019), Table S3: The onset $\mathrm{T}_{\text {gel }} \mathrm{S}$ of waxy corn starch in sweetener solutions grouped by similar solution solids content (same monomeric unit concentration) as follows: Group 1 contains $1 \mathrm{M}$ mono-, $0.5 \mathrm{M}$ disaccharide solutions; Group 2 contains $2 \mathrm{M}$ mono-, $1 \mathrm{M}$ disaccharide solutions; Group 3 contains $3 \mathrm{M}$ mono- and $1.5 \mathrm{M}$ disaccharide solutions; and Group 4 contains $4 \mathrm{M}$ mono- and $2 \mathrm{M}$ disaccharide, Figure S3: Waxy corn starch $\mathrm{T}_{\text {gel }}$ onsets in sweetener solutions in respect to the effective water content $\left(\varphi_{W}\right.$, eff) reported in van der Sman and Mauer (2019), Table S4: The onset $\mathrm{T}_{\text {gel }} \mathrm{S}$ of dent corn starch in sweetener solutions grouped by similar solution solids content (same monomeric unit concentration) as follows: Group 1 contains $1 \mathrm{M}$ mono-, $0.5 \mathrm{M}$ disaccharide solutions; Group 2 contains $2 \mathrm{M}$ mono-, $1 \mathrm{M}$ disaccharide solutions; Group 3 contains $3 \mathrm{M}$ mono- and $1.5 \mathrm{M}$ disaccharide solutions; and Group 4 contains 4 $\mathrm{M}$ mono- and $2 \mathrm{M}$ disaccharide, Figure S4: Dent corn starch $\mathrm{T}_{\text {gel }}$ onsets in sweetener solutions in respect to the effective water content $\left(\varphi_{W}\right.$, eff $)$ reported in van der Sman and Mauer (2019), Table S5: The onset $\mathrm{T}_{\text {gel }} \mathrm{S}$ of HACS55 starch in sweetener solutions grouped by similar solution solids content (same monomeric unit concentration) as follows: Group 1 contains 1M mono-, $0.5 \mathrm{M}$ disaccharide solutions; Group 2 contains $2 \mathrm{M}$ mono-, $1 \mathrm{M}$ disaccharide solutions; Group 3 contains $3 \mathrm{M}$ mono- and $1.5 \mathrm{M}$ disaccharide solutions; and Group 4 contains $4 \mathrm{M}$ mono- and 2 M disaccharide, Figure S5: HACS55 $\mathrm{T}_{\text {gel }}$ onsets in sweetener solutions in respect to the effective water content $\left(\varphi_{W}\right.$, eff $)$ reported in van der Sman and Mauer (2019), Table S6: The onset $\mathrm{T}_{\text {gel }} \mathrm{S}$ of HACS70 starch in sweetener solutions grouped by similar solution solids content (same monomeric unit concentration) as follows: Group 1 contains 1M mono-, $0.5 \mathrm{M}$ disaccharide solutions; Group 2 contains $2 \mathrm{M}$ mono-, $1 \mathrm{M}$ disaccharide solutions; Group 3 contains $3 \mathrm{M}$ mono- and $1.5 \mathrm{M}$ disaccharide solutions; and Group 4 contains $4 \mathrm{M}$ mono- and $2 \mathrm{M}$ disaccharide, Figure S6: HACS70 $T_{\text {gel }}$ onsets in sweetener solutions in respect to the effective water content $\left(\varphi_{W}\right.$, eff $)$ reported in van der Sman and Mauer (2019), Table S7: The onset $\mathrm{T}_{\text {gel }} \mathrm{s}$ of potato starch in sweetener solutions grouped by similar solution solids content (same monomeric unit concentration) as follows: Group 1 contains $1 \mathrm{M}$ mono-, 0.5 M disaccharide solutions; Group 2 contains $2 \mathrm{M}$ mono-, $1 \mathrm{M}$ disaccharide solutions; Group 3 contains $3 \mathrm{M}$ monoand $1.5 \mathrm{M}$ disaccharide solutions; and Group 4 contains $4 \mathrm{M}$ mono- and $2 \mathrm{M}$ disaccharide, Figure S7: Potato starch $\mathrm{T}_{\text {gel }}$ onsets in sweetener solutions in respect to the effective water content $\left(\varphi_{W}\right.$, eff $)$ reported in van der Sman and Mauer (2019), Table S8: Comparisons of correlation coefficients (R) of the $\log T_{\text {gel }}$ slopes and $\Delta T_{\text {gel }(i-0)} s$ in $3 \mathrm{M}$ monomeric unit concentrations $\left(\Delta \mathrm{T}_{\text {gel(3M-0) }}\right)$ of a sweetener in respect to the amylose contents of starches, Table $S 9$ : Averages with 1 standard deviation and $\mathrm{P}$ value of $\log \mathrm{T}_{\text {gel }} \mathrm{S}$ and $\Delta \mathrm{T}_{\text {gel }(3 \mathrm{M}-0)}$ in $\mathrm{A}$ and B-type starches.

Author Contributions: Conceptualization, M.C.A. and L.J.M.; methodology, M.C.A. and L.J.M.; software, M.C.A.; validation, M.C.A. and M.C.; formal analysis, M.C.A.; investigation, M.C.; resources, L.J.M.; data curation, M.C.A. and M.C.; writing — original draft preparation, M.C.A.; writing—review and editing, L.J.M.; visualization, M.C.A. and M.C.; supervision, M.C.A. and L.J.M.; project administration, M.C.A.; funding acquisition, L.J.M. All authors have read and agreed to the published version of the manuscript.

Funding: This research was supported by Post Doctoral Fellowships grant no. GRANT12433278/project accession no. IND011699G from the USDA National Institute of Food and Agriculture.

Acknowledgments: This work was supported by the Whistler Center for Carbohydrate Research at Purdue University and the James and Pari BeMiller Graduate Scholarship. A special thanks to ADM and Ingredion for donating the starches.

Conflicts of Interest: The authors declare no conflict of interest.

\section{References}

1. Huber, K.C.; BeMiller, J.N. Carbohydrates. In Fennema's Food Chemistry, 5th ed.; Damodaran, S., Parkin, K.L., Eds.; CRC Press: New York, NY, USA, 2017; pp. 91-169.

2. Jane, J. Structural features of starch granules II. In Starch: Chemistry and Technology, 3rd ed.; BeMiller, J.N., Whistler, R.L., Eds.; Academic Press: New York, NY, USA, 2009; pp. 193-236.

3. Tester, R.F.; Karkalas, J.; Qi, X. Starch-Composition, fine structure and architecture. J. Cereal Sci. 2004, 39, 151-165. [CrossRef] 
4. Perez, S.; Baldwin, P.M.; Gallant, D.J. Structural features of starch granules I. In Starch: Chemistry and Technology, 3rd ed.; BeMiller, J.N., Whistler, R.L., Eds.; Academic Press: New York, NY, USA, 2009; pp. 149-192.

5. Jenkins, P.J.; Cameron, R.E.; Donald, A.M. A universal feature in the structure of starch granules from different botanical sources. Starch-Stärke 1993, 45, 417-420. [CrossRef]

6. Gallant, D.J.; Bouchet, B.; Baldwin, P.M. Microscopy of starch: Evidence of a new level of granule organization. Carbohydr. Polym. 1997, 32, 177-191. [CrossRef]

7. Zeleznak, K.; Hoseney, R. The glass transition in starch. Cereal Chem. 1987, 64, 121-124.

8. Ratnayake, W.S.; Jackson, D.S. Starch gelatinization. Adv. Food Nutr. Res. 2008, 55, 221-268.

9. Perry, P.; Donald, A. The role of plasticization in starch granule assembly. Biomacromolecules 2000, 1, 424-432. [CrossRef]

10. Donovan, J.W. Phase transitions of the starch-water system. Biopolymers 1979, 18, 263-275. [CrossRef]

11. Vamadevan, V.; Bertoft, E.; Seetharaman, K. On the importance of organization of glucan chains on thermal properties of starch. Carbohydr. Polym. 2013, 92, 1653-1659. [CrossRef]

12. Pfannemüller, B. Influence of chain length of short monodisperse amyloses on the formation of A-and B-type X-ray diffraction patterns. Int. J. Biol. Macromol. 1987, 9, 105-108. [CrossRef]

13. Genkina, N.K.; Wikman, J.; Bertoft, E.; Yuryev, V.P. Effects of Structural Imperfection on Gelatinization Characteristics of Amylopectin Starches with A- and B-Type Crystallinity. Biomacromolecules 2007, 8, 2329-2335. [CrossRef]

14. Shi, Y.-C.; Seib, P.A. The structure of four waxy starches related to gelatinization and retrogradation. Carb. Res. 1992, 227, 131-145. [CrossRef]

15. Noda, T.; Isono, N.; Krivandin, A.V.; Shatalova, O.V.; Błaszczak, W.; Yuryev, V.P. Origin of defects in assembled supramolecular structures of sweet potato starches with different amylopectin chain-length distribution. Carbohydr. Polym. 2009, 76, 400-409. [CrossRef]

16. Liu, H.; Yu, L.; Xie, F.; Chen, L. Gelatinization of cornstarch with different amylose/amylopectin content. Carbohydr. Polym. 2006, 65, 357-363. [CrossRef]

17. Fredriksson, H.; Silverio, J.; Andersson, R.; Eliasson, A.C.; Åman, P. The influence of amylose and amylopectin characteristics on gelatinization and retrogradation properties of different starches. Carbohydr. Polym. 1998, 35, 119-134. [CrossRef]

18. Zhu, F. Relationships between amylopectin internal molecular structure and physicochemical properties of starch. Trends Food Sci. Technol. 2018, 78, 234-242. [CrossRef]

19. Vandeputte, G.E.; Vermeylen, R.; Geeroms, J.; Delcour, J.A. Rice starches. I. Structural aspects provide insight into crystallinity characteristics and gelatinisation behaviour of granular starch. J. Cereal Sci. 2003, 38, 43-52. [CrossRef]

20. Gomand, S.; Lamberts, L.; Derde, L.; Goesaert, H.; Vandeputte, G.; Goderis, B.; Visser, R.; Delcour, J. Structural properties and gelatinisation characteristics of potato and cassava starches and mutants thereof. Food Hydrocolloids 2010, 24, 307-317. [CrossRef]

21. Evans, I.; Haisman, D. The effect of solutes on the gelatinization temperature range of potato starch. Starch-Stärke 1982, 34, 224-231. [CrossRef]

22. Spies, R.D.; Hoseney, R.C. Effect of sugars on starch gelatinization. Cereal Chem. 1982, 59, $128-131$.

23. Beleia, A.; Miller, R.A.; Hoseney, R.C. Starch gelatinization in sugar solutions. Starch-Stärke 1996, 48, $259-262$. [CrossRef]

24. Slade, L.; Levine, H. Non-equilibrium melting of native granular starch: Part I. Temperature location of the glass transition associated with gelatinization of A-type cereal starches. Carbohydr. Polym. 1988, 8, 183-208. [CrossRef]

25. Slade, L.; Levine, H. Non-equilibrium behavior of small carbohydrate-water systems. Pure Appl. Chem. 1988, 60, 1841-1864. [CrossRef]

26. Hansen, L.; Setser, C.; Paukstelis, J. Investigations of sugar-starch interactions using carbon-13 nuclear magnetic resonance. I. sucrose. Cereal Chem. 1989, 66, 411-415.

27. Hoover, R.; Senanayake, N. Effect of sugars on the thermal and retrogradation properties of oat starches. J. Food Biochem. 1996, 20, 65-83. [CrossRef]

28. Perry, P.; Donald, A. The effect of sugars on the gelatinisation of starch. Carbohydr. Polym. 2002, 49, 155-165. [CrossRef] 
29. Allan, M.C.; Rajwa, B.; Mauer, L.J. Effects of sugars and sugar alcohols on the gelatinization temperature of wheat starch. Food Hydrocolloids 2018, 84, 593-607. [CrossRef]

30. Van der Sman, R.G.M.; Mauer, L.J. Starch gelatinization temperature in sugar and polyol solutions explained by hydrogen bond density. Food Hydrocolloids 2019, 94, 371-380. [CrossRef]

31. Cheetham, N.W.H.; Tao, L. Variation in crystalline type with amylose content in maize starch granules: An X-ray powder diffraction study. Carbohydr. Polym. 1998, 36, 277-284. [CrossRef]

32. Bertoft, E.; Koch, K.; Åman, P. Building block organisation of clusters in amylopectin from different structural types. Int. J. Biol. Macromol. 2012, 50, 1212-1223. [CrossRef]

33. Peymanpour, G.; Marcone, M.; Ragaee, S.; Tetlow, I.; Lane, C.C.; Seetharaman, K.; Bertoft, E. On the molecular structure of the amylopectin fraction isolated from "high-amylose" ae maize starches. Int. J. Biol. Macromol. 2016, 91, 768-777. [CrossRef]

34. Lopez-Rubio, A.; Flanagan, B.M.; Gilbert, E.P.; Gidley, M.J. A novel approach for calculating starch crystallinity and its correlation with double helix content: A combined XRD and NMR study. Biopolym. Orig. Rese. Biomol. 2008, 89, 761-768. [CrossRef] [PubMed]

35. Bertoft, E. Composition of building blocks in clusters from potato amylopectin. Carbohydr. Polym. 2007, 70, 123-136. [CrossRef]

36. Kalinga, D.N.; Bertoft, E.; Tetlow, I.; Seetharaman, K. Structure of clusters and building blocks in amylopectin from developing wheat endosperm. Carbohydr. Polym. 2014, 112, 325-333. [CrossRef] [PubMed]

37. Eliasson, A.C. Effect of water content on the gelatinization of wheat starch. Starch-Stärke 1980, 32, $270-272$. [CrossRef]

38. BeMiller, J.N. Carbohydrate Chemistry for Food Scientists., 3rd ed.; Elsevier: Cambridge, MA, USA, 2018.

39. Shahidi, F.; Farrell, P.G.; Edward, J.T. Partial molar volumes of organic compounds in water. III. Carbohydrates. J. Solut. Chem. 1976, 5, 807-816. [CrossRef]

40. Buttersack, C. Hydrophobicity of carbohydrates and related hydroxy compounds. Carb. Res. 2017, 446, 101-112. [CrossRef]

41. Høiland, H.; Holvik, H. Partial molal volumes and compressibilities of carbohydrates in water. J. Solut. Chem. 1978, 7, 587-596. [CrossRef]

42. Shamil, S.; Birch, G.; Mathlouthi, M.; Clifford, M. Apparent molar volumes and tastes of molecules with more than one sapophore. Chem. Senses 1987, 12, 397-409. [CrossRef]

43. Jiang, X.; Zhu, C.; Ma, Y. Density and viscosity of sorbitol/maltitol in L-ascorbic acid aqueous solutions at $\mathrm{T}=(293.15$ to 323.15)K. J. Mol. Liq. 2013, 188, 67-73. [CrossRef]

44. Jang, J.; Pyun, Y. Effect of moisture content on the melting of wheat starch. Starch-Stärke 1996, 48, 48-51. [CrossRef]

45. Stoddart, J.F. Stereochemistry of Carbohydrates; John Wiley \& Sons, Inc.: Hoboken, NJ, USA, 1971.

46. Uedaira, H.; Ishimura, M.; Tsuda, S.; Uedaira, H. Hydration of oligosaccharides. Bull. Chem. Soc. Jpn. 1990, 63, 3376-3379. [CrossRef]

47. Miljković, M. Relative reactivity of hydroxyl groups in monosaccharides. In Carbohydrates: Synthesis, Mechanisms, and Stereoelectronic Effects; Miljković, M., Ed.; Springer: New York, NY, USA, 2010; pp. 113-142.

48. Hsieh, C.-F.; BeMiller, J.N.; Huber, K.C. Impact of granule hydration on maize and wheat starch chemical reactivity at the granular and molecular levels. Food Hydrocoll. 2019, 105374. [CrossRef]

49. Van der Sman, R.G.M. Predictions of glass transition temperature for hydrogen bonding biomaterials. J. Phys. Chem. B 2013, 117, 16303-16313. [CrossRef] [PubMed]

50. Baek, M.H.; Yoo, B.; Lim, S.T. Effects of sugars and sugar alcohols on thermal transition and cold stability of corn starch gel. Food Hydrocoll. 2004, 18, 133-142. [CrossRef]

51. Morrison, W.R.; Tester, R.F.; Snape, C.E.; Law, R.; Gidley, M. Swelling and gelatinization of cereal starches. IV. Some effects of lipid-complexed amylose and free amylose in waxy and normal barley starches. Cereal Chem. 1993, 70, 385.

52. Matveev, Y.I.; Van Soest, J.; Nieman, C.; Wasserman, L.; Protserov, V.; Ezernitskaja, M.; Yuryev, V. The relationship between thermodynamic and structural properties of low and high amylose maize starches. Carbohydr. Polym. 2001, 44, 151-160. [CrossRef]

53. Biliaderis, C.G.; Page, C.M.; Maurice, T.J.; Juliano, B.O. Thermal characterization of rice starches: A polymeric approach to phase transitions of granular starch. J. Agric. Food Chem. 1986, 34, 6-14. [CrossRef] 
54. Juliano, B.; Perez, C. Crystallinity of raw rice starch granules as indexed by corrosion with hydrochloric acid and amylase. Starch-Stärke 1990, 42, 49-52. [CrossRef]

55. Noda, T.; Takahata, Y.; Sato, T.; Suda, I.; Morishita, T.; Ishiguro, K.; Yamakawa, O. Relationships between chain length distribution of amylopectin and gelatinization properties within the same botanical origin for sweet potato and buckwheat. Carbohydr. Polym. 1998, 37, 153-158. [CrossRef]

56. Karim, A.; Toon, L.; Lee, V.; Ong, W.; Fazilah, A.; Noda, T. Effects of phosphorus contents on the gelatinization and retrogradation of potato starch. J. Food Sci. 2007, 72, C132-C138. [CrossRef]

57. Wang, W.; Zhou, H.; Yang, H.; Zhao, S.; Liu, Y.; Liu, R. Effects of salts on the gelatinization and retrogradation properties of maize starch and waxy maize starch. Food Chem. 2017, 214, 319-327. [CrossRef] [PubMed]

58. Shi, Y.-C.; Seib, P.A. Fine structure of maize starches from four wx-containing genotypes of the W64A inbred line in relation to gelatinization and retrogradation. Carbohydr. Polym. 1995, 26, 141-147. [CrossRef]

59. Li, G.; Zhu, F. Amylopectin molecular structure in relation to physicochemical properties of quinoa starch. Carbohydr. Polym. 2017, 164, 396-402. [CrossRef] [PubMed]

60. Kong, X.; Bertoft, E.; Bao, J.; Corke, H. Molecular structure of amylopectin from amaranth starch and its effect on physicochemical properties. Int. J. Biol. Macromol. 2008, 43, 377-382. [CrossRef] [PubMed]

61. Hanashiro, I.; Abe, J.-I.; Hizukuri, S. A periodic distribution of the chain length of amylopectin as revealed by high-performance anion-exchange chromatography. Carb. Res. 1996, 283, 151-159. [CrossRef]

62. Hizukuri, S. Polymodal distribution of the chain lengths of amylopectins, and its significance. Carb. Res. 1986, 147, 342-347. [CrossRef]

63. Donald, A.M.; Perry, P.A.; Waigh, T.A. The impact of internal granule structure on processing and properties. In Starch: Advances in Structure and Function; Barsby, T.L., Donald, A.M., Frazier, P.J., Eds.; Royal Society of Chemistry: Cambridge, UK, 2001; Volume 271, pp. 45-52.

64. Ai, Y.; Jane, J.-1. Understanding starch structure and functionality. In Starch in Food, 2nd ed.; Sjöö, M., Nilsson, L., Eds.; Elsevier: Amsterdam, The Netherlands, 2018; pp. 151-178.

65. Semeijn, C.; Buwalda, P.L. Potato Starch. In Starch in Food; Elsevier: Amsterdam, The Netherlands, 2018; pp. 353-372.

66. Jane, J.; Chen, Y.; Lee, L.; McPherson, A.; Wong, K.; Radosavljevic, M.; Kasemsuwan, T. Effects of amylopectin branch chain length and amylose content on the gelatinization and pasting properties of starch. Cereal Chem. 1999, 76, 629-637. [CrossRef]

67. Blennow, A.; Bay-Smidt, A.M.; Olsen, C.E.; Møller, B.L. The distribution of covalently bound phosphate in the starch granule in relation to starch crystallinity. Int. J. Biol. Macromol. 2000, 27, 211-218. [CrossRef]

68. Weast, R.C. Handbook of Chemistry and Physics; 1st student ed.; CRC Press: Boca Raton, FL, USA, 1988.

69. Marsh, R.; Waight, S. The effect of $\mathrm{pH}$ on the zeta potential of wheat and potato starch. Starch-Stärke 1982, 34, 149-152. [CrossRef]

70. Huber, K.C.; BeMiller, J.N. Location of sites of reaction within starch granules. Cereal Chem. 2001, 78, 173-180. [CrossRef]

71. Lim, S.; Seib, P. Location of Phosphate Esters in a Wheat Starch Phosphate by 31P-Nuclear Magnetic Resonance Spectroscopy. Cereal Chem. 1993, 70, 145.

72. Takeda, Y.; Hizukuri, S. Location of phosphate groups in potato amylopectin. Carb. Res. 1982, 102, $321-327$. [CrossRef]

73. McPherson, A.E.; Jane, J. Comparison of waxy potato with other root and tuber starches. Carbohydr. Polym. 1999, 40, 57-70. [CrossRef]

74. Mali, S.; Ferrero, C.; Redigonda, V.; Beleia, A.P.; Grossmann, M.V.E.; Zaritzky, N.E. Influence of pH and hydrocolloids addition on yam (Dioscorea alata) starch pastes stability. LWT Food Sci. Technol. 2003, 36, 475-481. [CrossRef]

(C) 2020 by the authors. Licensee MDPI, Basel, Switzerland. This article is an open access article distributed under the terms and conditions of the Creative Commons Attribution (CC BY) license (http://creativecommons.org/licenses/by/4.0/). 